\title{
Discussion Paper No. 18-017 \\ The Demand for Global and Local Environmental Protection - Experimental Evidence from Climate Change Mitigation in Beijing
}

Andreas Loeschel, Jiansuo Pei, Bodo Sturm, Ran Wang,

Wolfgang Buchholz, and Zhongxiu Zhao

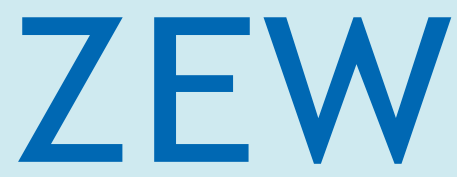

Zentrum für Europäische Wirtschaftsforschung $\mathrm{GmbH}$

Centre for European

Economic Research 


\title{
Discussion Paper No. 18-017 \\ The Demand for Global and Local Environmental Protection - Experimental Evidence from Climate Change Mitigation in Beijing
}

\author{
Andreas Loeschel, Jiansuo Pei, Bodo Sturm, Ran Wang, \\ Wolfgang Buchholz, and Zhongxiu Zhao
}

Download this ZEW Discussion Paper from our ftp server:

http://ftp.zew.de/pub/zew-docs/dp/dp18017.pdf

Die Discussion Papers dienen einer möglichst schnellen Verbreitung von neueren Forschungsarbeiten des ZEW. Die Beiträge liegen in alleiniger Verantwortung der Autoren und stellen nicht notwendigerweise die Meinung des ZEW dar.

Discussion Papers are intended to make results of ZEW research promptly available to other economists in order to encourage discussion and suggestions for revisions. The authors are solely responsible for the contents which do not necessarily represent the opinion of the ZEW. 


\title{
The Demand for Global and Local Environmental Protection - Experimental Evidence from Climate Change Mitigation in Beijing
}

\author{
Andreas Loeschel* \\ (University of Muenster and ZEW Mannheim) \\ Jiansuo Pei \\ (UIBE Beijing) \\ Bodo Sturm \\ (Leipzig University of Applied Sciences and ZEW Mannheim) \\ Ran Wang \\ (UIBE Beijing) \\ Wolfgang Buchholz \\ (University of Regensburg) \\ Zhongxiu Zhao \\ (UIBE Beijing)
}

April 2018

\begin{abstract}
In this study, the real demand for global and local environmental protection in Beijing, China, is elicited and investigated. Participants from Beijing were offered the opportunity to contribute to voluntary climate change mitigation by purchasing permits from two Chinese $\mathrm{CO}_{2}$ emissions trading schemes (ETS). Purchased permits were withdrawn from the ETS. Since $\mathrm{CO}_{2}$ emissions mitigation is inevitably linked to other local benefits like the reduction in emissions of air pollutants, the aim of our study is to establish the demand for local and global environmental protection. To this end, Beijing and Shenzhen ETS permits were offered. The result is that at low prices the demand for Beijing ETS permits is significantly higher than for Shenzhen ETS permits indicating that a substantial part of the revealed demand for voluntary climate change mitigation in Beijing is driven by concerns for local co-benefits of $\mathrm{CO}_{2}$ emissions reduction. Our research identifies the important role of private benefits in the voluntary provision of the global public good climate change mitigation and provides first experimental evidence for China.
\end{abstract}

Keywords: demand for environmental protection, experimental economics, willingness to pay, China; voluntary climate change mitigation, co-benefits

JEL-Classification: Q51, Q54, C93

\footnotetext{
* Corresponding Author: Andreas Löschel, Chair of Microeconomics with a Focus on Energy and Resource Economics, email: loeschel@uni-muenster.de, Am Stadtgraben 9, 48143 Münster, Germany. Phone: +49(0)251-83-25004. Financial support by the UIBE Beijing is gratefully acknowledged. We thank workshop participants at Tianjin University, UFZ Leipzig, ZEW Mannheim and Martin Achtnicht, Carlo Gallier, Andrea Gauselmann and Ian Mills for valuable comments.
} 


\section{Introduction}

Local air pollution is one of the most urgent environmental problems in emerging countries. China is a prominent example. Here, coal combustion, originating from industry, power generation and residential sources, is the single largest source of air pollution-related health impacts, and is estimated to have contributed to 366,000 premature deaths in China in 2013 (HEI 2016). The most harmful local pollutants emitted from Chinese coal-fired power plants are $\mathrm{SO}_{2}, \mathrm{NO}_{\mathrm{X}}$ and particulate matter $\left(\mathrm{PM}_{2.5 / 10}\right)$ (Zhao et al. 2008). The different meteorological, geographic and climatic conditions as well as the differences in the intensity of emissions results in the concentration of local pollutants differing considerably across the country. Fine particulate matter $\mathrm{PM}_{2.5}$, for example, is a major cause of air pollution and the local concentrations in Chinese cities are substantially different across the country; these are typically much higher than in cities of developed countries. ${ }^{1}$

However, China does not only struggle with severe local environmental problems. The country is also the world's largest emitter of $\mathrm{CO}_{2}$. Since climate change mitigation is a global public good, a strong free-rider incentive exists which make an international cooperative solution highly unlikely. There is, however, an intense debate about private "co-benefits" from climate change mitigation. According to the IPCC (2014a), co-benefits are defined as the positive effects that a policy or measure aimed at one objective might have on other objectives. Co-benefits are also referred to as ancillary benefits. Deng et al. (2017) provide a systematic review of the fast growing research on co-benefits of reducing greenhouse gas emissions and classify them by co-benefit type, mitigation sector, and geographic scope. Cobenefits from climate change mitigation policies include impacts on ecosystems, economic activity, air pollution, health, resource efficiency, energy security, and technological spillover and innovation. Some of these co-benefits of climate mitigation are clearly local. According to the IPCC (IPCC 2014b, p. 63), for example, “[climate] mitigation scenarios ... are associated with significant co-benefits for air quality and related human health".

These co-benefits from air pollution and health are particularly relevant for emerging countries with weak regulation of local pollutants. Therefore, it is expected that countries such as China have, beside their limited primary incentives to contribute to the global public good climate change mitigation, an additional incentive to mitigate $\mathrm{CO}_{2}$ emissions as those emissions reductions are inevitably linked to reductions of local pollutants (Haines 2017,

1 As an example: According to WHO data (for 2013/14) the annual mean for $\mathrm{PM}_{2.5}$ and $\mathrm{PM}_{10}$ in Beijing (Shenzhen) was 85 and $108 \mu \mathrm{g} / \mathrm{m}^{3}$ (34 and $61 \mu \mathrm{g} / \mathrm{m}^{3}$ ). In Berlin, Germany, the annual mean was 16 and 10 $\mu \mathrm{g} / \mathrm{m}^{3}$ (WHO 2016). 
Zhang et al. 2017a). The reduction of coal use through a carbon tax or an emissions trading system, for example, would lead to co-benefits from less $\mathrm{PM}_{2.5 / 10}$ or $\mathrm{SO}_{2}$. Thus, from the Chinese perspective there are private co-benefits at the local level from contribution to the global public good and China's contribution to climate change mitigation might be partly motivated by these local co-benefits.

Against this background, the central research question of our paper is whether it is possible to isolate and quantify local co-benefits from climate change mitigation in real individual behavior. For this purpose, we apply a revealed preference framework and make use of the initiation of seven pilot emissions trading schemes (ETS) in China (Jotzo and Löschel 2014). Participants from Beijing were offered the opportunity to contribute to voluntary climate change mitigation by purchasing permits from two separate sub-national Chinese $\mathrm{CO}_{2}$ emissions trading schemes in Beijing and Shenzhen. Purchased permits were withdrawn from the respective ETS. Hence, $\mathrm{CO}_{2}$ emissions are reduced locally in the respective region leading to local co-benefits. However, due to the distance between both sub-national trading schemes (Shenzhen is situated more than $2000 \mathrm{~km}$ south of Beijing) it is highly unlikely that reduced $\mathrm{CO}_{2}$ emissions in Shenzhen cause positive co-benefits in Beijing. On the other hand, the effects of the mitigation of $\mathrm{CO}_{2}$, a uniformly mixed fund pollutant whose damage depends only on the total amount of $\mathrm{CO}_{2}$ in the atmosphere, not on the location of the emission, are identical in both cases. As the $\mathrm{CO}_{2}$ emissions reduction only leads to a reduced imposition of local air pollutants or other local co-benefits for our participants in Beijing, we are able to establish the real demand for global as well as for local environmental protection. To our knowledge, we provide the first empirical assessment of the willingness to contribute to additional global and local environmental protection based on an experimental approach.

Our main results can be summarized as follow: (i) Contrary to standard economic theory, Chinese individuals contribute to $\mathrm{CO}_{2}$ reduction even though marginal benefit of contributing is zero while costs are positive. (ii) There is an additional demand for $\mathrm{CO}_{2}$ reduction stemming from local co-benefits, i.e. more individuals contribute to climate mitigation and the median willingness to pay is higher when local co-benefits are taken into account. Our results, thus, support the hypothesis that China has an additional motivation in contributing to mitigate climate change. For small prices up to the median, the willingness to pay for $\mathrm{CO}_{2}$ reduction is even mainly driven by these local co-benefits. (iii) The proportion of subjects who contribute to climate change mitigation quickly decreases with price. In contrast to recent literature from developed countries, the demand for $\mathrm{CO}_{2}$ reduction in China seems to be rather elastic. 
The paper is organized as follows. Section 2 presents the related literature. The experimental design is described in Section 3. In Section 4 we derive hypotheses regarding individual behavior. We discuss our results in Section 5, before concluding in Section 6.

\section{Related literature}

In economics literature, public goods are regularly treated as pure public goods, characterized by perfect non-excludability and non-rivalry, although most public goods are not "purely public". The main reason for doing so is the simplicity of pure public goods analysis. In reality, almost every global public good provision represents a joint production of several characteristics of different degrees of publicness, i.e. global public goods production is usually an impure public goods production. Mitigating climate change as a global public good may serve as an example as it is neither entirely non-rivalrous nor non-excludable. Besides the primary benefits from reducing $\mathrm{CO}_{2}$ emissions, private co-benefits such as reduced local air pollution are generated. Figure 1 describes our underlying approach based on theoretical impure public good models (Rübbelke 2003, Cornes and Sandler 1994).

Reduction of Beijing ETS cap by $1 \mathrm{tCO}_{2}$

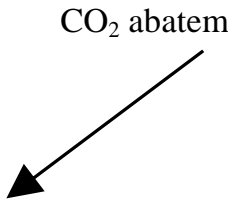

Pure public characteristic: reduction of $\mathrm{CO}_{2}$ emissions

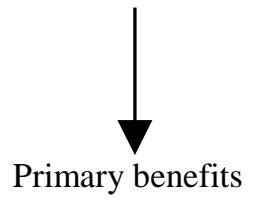

Private characteristic e.g. reduction of $\mathrm{PM}_{2.5 / 10}$ emissions

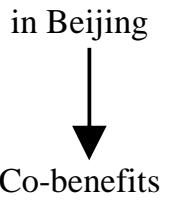

Reduction of Shenzhen ETS cap by $1 \mathrm{tCO}_{2}$

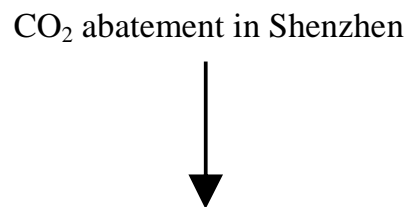

Pure public characteristic: reduction of $\mathrm{CO}_{2}$ emissions

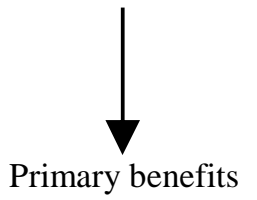

Source: Own illustration based on Rübbelke (2003)

Figure 1: Primary and co-benefits from climate change mitigation

As the experiment was conducted in Beijing, we use this as our baseline treatment (termed Beijing) and the economic activity can be represented by the reduction of the cap of the Beijing ETS by $1 \mathrm{tCO}_{2}$. The corresponding $\mathrm{CO}_{2}$ abatement generates two benefits for these subjects: A primary (public) benefit from the reduction of $\mathrm{CO}_{2}$ emissions and (private) cobenefit, e.g. from reducing local air pollution, based on their geographic proximity. In our secondary treatment (termed Shenzhen), subjects were offered the opportunity to reduce the cap by $1 \mathrm{tCO}_{2}$ for the Shenzhen ETS; in this case it can be assumed that the sole benefit of 
such a transaction is that of the generation of a public good provision on account of the distance between the two cities.

Let us briefly consider the decision situation from this stylized theoretical perspective. Assume that there are two distant locations, $i$ and $j$. In our case, $i$ denotes Beijing and $j$ Shenzhen. Consider location $i$. The utility of a representative agent in location $i$ is

$$
U\left(m_{i}, g_{i}, g_{j}\right):=u\left(m_{i}\right)+v\left(g_{i}+g_{j}\right)+w\left(g_{i}+d_{i j} g_{j}\right)
$$

where $m_{i}$ is the agent $i$ 's income, $g_{i}$ is the environmental good produced in $i$, and $g_{j}$ the environmental good produced in $j$. The first utility component $u\left(m_{i}\right)$ is obtained as the indirect utility function, when we assume that the representative agent maximizes her standard utility function being defined over the vector of consumption goods given her income $m_{i}$ and the market prices of these consumption goods (see, e.g., Ebert 1993, 2003). The environmental good is $\mathrm{CO}_{2}$ emissions reduction. The agent's utility depends on the sum of $\mathrm{CO}_{2}$ emissions reductions in $i$ and $j$, which gives the second utility component $v\left(g_{i}+g_{j}\right)$. Reducing $\mathrm{CO}_{2}$ emissions at $i$ or $j$ also (linearly) lowers local emissions at $i$ or $j$, respectively, which is represented by the third utility component $w\left(g_{i}+d_{i j} g_{j}\right)$, i.e. the private co-benefits of public good provision. The parameter $d_{i j}$ is the impact or distance coefficient describing the effects of emissions reductions in $j$ on $i$. Since both locations are assumed to be far away from each other we can assume $0<d_{i j}<1$. $^{2}$

Given $\left(m_{i}, g_{i}, g_{j}\right)$ we now ask how much of her income agent $i$ would be willing to spend at most to obtain an additional marginal unit of the public good produced at the same location $i$. This maximum willingness to pay $\frac{-d m_{i}}{d g_{i}}$ is determined by the condition that utility $U\left(m_{i}, g_{i}, g_{j}\right)$ of agent $i$ is kept constant, i.e. that the condition

$$
\frac{\delta U}{\delta m_{i}} d m_{i}+\frac{\delta U}{\delta g_{i}} d g_{i}=0
$$

is satisfied. Hence, the marginal willingness to pay is given by

$$
W T P_{g_{i}}=\frac{-d m_{i}}{d g_{i}}=\frac{\delta U / \delta g_{i}}{\delta U / \delta m_{i}}=\frac{v^{\prime}\left(g_{i}+g_{j}\right)+w^{\prime}\left(g_{i}+d_{i j} g_{j}\right)}{u^{\prime}\left(m_{i}\right)}
$$

The $W T P_{g_{i}}$ can be interpreted as the virtual price of the environmental good, i.e. if $g_{i}$ were a market good, the consumers would be willing to pay this price for another unit (Baumgärtner et al. 2017). The marginal willingness to pay for the environmental good relates the marginal

2 Since Shenzhen is situated at the coast of the South China Sea more than 2,000 km south of Beijing, and the concentrations of local air pollutants in Shenzhen are rather low, in our case $d_{i j}$ is close to zero. See, e.g., Sun et al. (2015) for potential source contribution functions for fine particles in China. 
benefit of an additional unit of $g_{i}$ with the marginal cost of forgone consumption. This is the point of departure for our experimental approach.

For an emissions reduction in $j$ the marginal willingness to pay for an increase of $g_{j}$ for an agent in location $i$ is given accordingly by

$$
W T P_{g_{j}}=\frac{v^{\prime}\left(g_{i}+g_{j}\right)+d_{i j} w^{\prime}\left(g_{i}+d_{i j} g_{j}\right)}{u^{\prime}\left(m_{i}\right)}
$$

If $0<d_{i j}<1, W T P_{g_{i}}>W T P_{g_{j}}$. With $d_{i j} \rightarrow 0$ as in our case, the marginal willingness to pay for the agent in location $i$ for $\mathrm{CO}_{2}$ emissions reduction in $i, W T P_{g_{i}}$, is derived from the public good utility as well as from the private co-benefits of public good provision via, e.g., emissions reductions of local pollutants in $i$ only. The marginal willingness to pay for $\mathrm{CO}_{2}$ emissions reduction in $j$ for a consumer in $i, W T P_{g_{j}}$, is derived from the public good utility alone.

The empirical literature on impure public goods is extremely limited. Heisey et al. (1997) and Midler et al. (2015) investigate impure public good problems such as biodiversity in an agricultural context. Munro and Valente (2016) show by means of a laboratory experiment that green goods with impure public good characteristics do not necessarily enhance environmentally friendly behavior. Finally, Kotchen and Moore (2007) investigate why subjects participate in green-electricity programs and how a program's incentives affect participation.

There are, however, at least two other branches of empirical literature directly related to our study. First are the several revealed preferences studies which have recently explored the question of individual demand for voluntary climate change mitigation and derived WTP for climate change mitigation in monetary units per $\mathrm{tCO}_{2}$. Löschel et al. (2013) sold EU ETS permits at different prices to a sample of 202 subjects selected from the population of Mannheim, Germany. A median WTP of zero and a mean WTP of $12 € / \mathrm{tCO}_{2}$ is found. A similar framed field experiment with cash incentives was conducted by Diederich and Goeschl (2014) who determined the willingness to abate one $\mathrm{tCO}_{2}$ among the German Internet-using population. They estimate a zero median WTP and a mean WTP of about 6 $€ / \mathrm{tCO}_{2}$. Diederich and Goeschl (2017) estimated the elasticity of the probability of contributing to $\mathrm{CO}_{2}$ abatement for a German sample and found on average an inelastic price reaction. They conclude that, for Germany, using public funds to subsidize voluntary contributions to $\mathrm{CO}_{2}$ abatement is not economically meaningful. Using a similar revealed preference approach Uehleke and Sturm (2017) and Löschel et al. (2017) investigated whether 
the individual contribution to the global public good climate change mitigation depends on different degrees of collective action.

Secondly, there is an increasing number of papers devoted to the impact of local air pollution in emerging countries such as China on health and well-being from an economic perspective. Barwick et al. (2017) quantified the health impacts of $\mathrm{PM}_{2.5}$ in China and estimate consumer WTP for improved air quality. He et al. (2016) estimated the impact of $\mathrm{PM}_{10}$ on mortality during the 2008 Olympic Games in Beijing. Du et al. (2016) evaluated the impact of air pollution on life satisfaction. Using disaggregated air pollution data for $\mathrm{SO}_{2}, \mathrm{NO}_{2}, \mathrm{PM}_{2.5 / 10}$ and geo-coded individual respondents from original survey data, they showed that all four pollutants have significantly negative impacts on life satisfaction (see also Zhang et al. 2017b for a similar study).

Our study extends the literature by an innovative revealed preference approach to assess local co-benefits of climate change mitigation. Exploiting the existence of sub-national Chinese ETS, it is based on individual purchase decisions for Chinese ETS permits in two distant locations. Thereby, our approach opens a new way to the empirical evidence on local cobenefits from climate change mitigation.

\section{Experimental design}

The aim of our study was to investigate the extent to which a sample of the Beijing population would be willing to contribute to additional global and local environmental protection from their own disposable income. To elicit the demand for environmental protection, an experimental approach of asking people to give up real money instead of a survey approach was implemented. In order to address the impure public good problem both Beijing and Shenzhen ETS were employed as vehicles and emissions reductions were directly sold to the subjects. The main characteristics of both ETS are described in Table 1. For our purpose, it is particularly relevant that the ETS cap is binding, i.e. the price is positive, and the schemes are not linked. This means that by reducing the cap by $1 \mathrm{tCO}_{2}$ in Beijing or Shenzhen we can be sure that $\mathrm{CO}_{2}$ emissions are reduced by that amount in the respective ETS region.

Table 1: Basic facts on Beijing and Shenzhen ETS

\begin{tabular}{|c|c|c|c|c|}
\hline ETS & $\begin{array}{l}\text { Annual cap } \\
\text { in } \mathrm{mtCO}_{2}\end{array}$ & $\begin{array}{c}\text { Covered } \\
\text { entities }\end{array}$ & Main sectors covered & $\begin{array}{l}\text { Average price } \\
\text { in } \mathrm{RMB} / \mathrm{tCO}_{2}\end{array}$ \\
\hline Beijing & 55 & 543 & $\begin{array}{l}\text { Electricity, heating, cement, petrochemical and } \\
\text { other industries, large public buildings }\end{array}$ & 49 \\
\hline Shenzhen & 30 & 635 & $\begin{array}{l}\text { Electricity, building, manufacturing, } \\
\text { water supply }\end{array}$ & 29 \\
\hline
\end{tabular}


This section presents the experimental procedures, whereby the baseline treatment Beijing is used as a reference. Modifications in the second treatment Shenzhen are also explained. Participants were recruited by the University of International Business and Economics (UIBE Beijing, China) following the random distribution of approximately 8,000 letters of invitation within the $5^{\text {th }}$ ring of Beijing city, supplemented by a random online call-for-participation using the so-called WeChat service (see Appendix 1 for details). The information that people received at this stage was that a survey would be carried out in which they would have the opportunity to buy products and that they would receive remuneration of 300 RMB (about 40 $€)$ for their time. ${ }^{3}$ Registration was done via telephone. To avoid subjects overstating their demand due to windfall money, the invitation letter emphasized that the amount of $300 \mathrm{RMB}$ was explicitly remuneration for participation in the survey and their travel expenses.

To elicit the individual demand a simple and incentive compatible market mechanism was chosen (see Appendix 2 for instructions): Each participant was confronted with six different prices for permits in $1 \mathrm{tCO}_{2}$ units ordered from 'high' to 'low'. Subjects had to decide whether they would be willing to buy at each of the prices. Finally, one of the six prices was randomly and openly selected by rolling a dice and the transaction was carried out at the corresponding price in privacy. Participants who did not wish to buy at a specific price indicated this with "NO".

The experiment took place in March 2017 in the labs of the UIBE in Beijing, China. A total of 317 participants took part in the experiment and were randomly allocated to 11 sessions (each with between 17 and 32 participants). The steps of the experiment are listed in Table 2 below. At the beginning of each session, participants received $300 \mathrm{RMB}$ in cash and signed and confirmed that they would obey the rules given by the research staff during the study (see letter of understanding in Appendix 1).

3 According to Beijing Municipal Bureau of Statistics, the GDP per capita in Beijing in 2015 is 106,497 RMB (292 RMB per day). The average wage of workers in Beijing in 2016 is 92,477 RMB (253 RMB per day). 
Table 2: Steps of the experiment

\begin{tabular}{|c|c|c|}
\hline \multirow[b]{2}{*}{ \# } & & \\
\hline & Step & Explanation \\
\hline 1 & Welcome & $\begin{array}{l}\text { Issuing of instructions and hand-out of } 300 \mathrm{RMB} \text {, confirmation of compliance } \\
\text { with rules }\end{array}$ \\
\hline 2 & Questionnaire I & Socio-economic characteristics and attitudes towards climate change \\
\hline 3 & General information & Explanation and presentation of the purchase procedure \\
\hline 4 & Comprehension test & Example of purchase decision \\
\hline 5 & Information I & Climate change and co-benefits from $\mathrm{CO}_{2}$ reduction \\
\hline 6 & Information II & Beijing/Shenzhen ETS (depending on the treatment) \\
\hline 7 & Purchase decision & $\begin{array}{l}\text { Indicate for each price out of a set of six prices whether you are willing to } \\
\text { buy or not }\end{array}$ \\
\hline 8 & Questionnaire 2 & Expectations, opinions about climate policy and social norms \\
\hline 9 & Public price draw & Random selection of one price via rolling a dice \\
\hline 10 & Payment & Subjects pay their stated prices in private \\
\hline 11 & Leave the university & \\
\hline
\end{tabular}

Participants were asked to choose a desk from which to answer the survey and the instructions were then distributed. Participants were not permitted to communicate with one another. A research administrator and two research assistants were on hand during each session to clarify any questions that arose with the participant concerned. Each session lasted for approximately 90 minutes. At first, participants completed an initial questionnaire enquiring into their socioeconomic characteristics and attitudes towards climate change. The purchasing procedure was then explained by use of instructions (see Appendix 2). Additionally, participants witnessed a first presentation of a tangible (but unrelated to $\mathrm{CO}_{2}$ permits) example of the market mechanism and were asked to fill out a short test as verification of their understanding of the procedure. The explanation of the purchasing rule was included in the instructions. Following this stage, participants received information about (i) climate change and its effects on the environment and human society, including co-benefits from reduced emissions of local air pollutants, and (ii) the Beijing or Shenzhen ETS (depending on the treatment, see below). In the information about the ETS, emphasis was placed on the fact that buying and withdrawing permits reduces the ETS cap and thus $\mathrm{CO}_{2}$ emissions.

Finally, participants were informed that they had the opportunity to buy permits in $1 \mathrm{tCO}_{2}$ units with their own money and could therefore contribute to the overall reduction of $\mathrm{CO}_{2}$ emissions. Participants were reassured that all transactions would be carried out and that the final purchases and withdrawing of permits would be announced on the UIBE webpage. ${ }^{4}$ In order to make individual $\mathrm{CO}_{2}$ emissions more tangible, participants were provided with a second presentation with three specific examples of activities resulting in emissions of 
$1 \mathrm{tCO}_{2} \cdot{ }^{5}$ Thereafter, each participant was asked to indicate whether they would be willing to purchase the permit at each of the six different prices. Finally, participants completed a second questionnaire answering questions about expectations regarding others' behavior and the recent price for $\mathrm{CO}_{2}$ certificates, general opinions regarding climate policy and social norms. After the public price draw, participants left the room and the university individually. Subjects who had announced purchases of $1 \mathrm{tCO}_{2}$ permits paid the corresponding amount of money they had stated in the survey.

In treatment Beijing, subjects were given the opportunity to buy $1 \mathrm{tCO}_{2}$ in Beijing ETS at six different prices, both in scenarios with higher prices ("high") and lower prices ("low") (see Table 3). In treatment Shenzhen, analogously, $1 \mathrm{tCO}_{2}$ from Shenzhen ETS was sold. Subjects only took part in one treatment ("between-subjects design").

Table 3: Number of respondents in each treatment

\begin{tabular}{|c|c|c|c|c|}
\hline & & & & \\
\hline & & Beijing & Shenzhen & $\sum$ \\
\hline Price vector & Low & 107 & 49 & $1 \overline{56}$ \\
\hline Price vector & High & 155 & 46 & 161 \\
\hline & $\sum$ & 222 & 95 & 317 \\
\hline
\end{tabular}

Note: In the treatment Beijing Beijing ETS certificates were sold. In treatment Shenzhen Shenzhen ETS certificates were sold. In Beijing 60 subjects for each price vector faced a $2^{\text {nd }}$ decision situation after their purchase decision. This $2^{\text {nd }}$ decision situation is not considered here. The low (high) price vector is in RMB: $\{2$, $9,20,35,70,200\}(\{5,14,27,45,100,300\})$.

The total quantity of allowances purchased by the participants equated to $60 \mathrm{tCO}_{2}$ (incl. Beijing ETS $55 \mathrm{tCO}_{2}$ and Shenzhen ETS $5 \mathrm{tCO}_{2}$ ). This amount of permits was bought and then deleted. ${ }^{6}$ The revenue collected by those subjects who completed transactions totaled 1,184 RMB. The entire process was published at the UIBE webpage.

\section{Hypotheses}

We start the discussion of the hypothesized behavior with the treatment Shenzhen. Since subjects living in Beijing are barely affected by co-benefits in Shenzhen such as reduced local air pollution, contributions in this treatment are in practice solely motivated by climate change concerns (see our stylized theoretical framework in Section 2). Standard economic theory based on selfishness predicts zero contributions to the global public good of climate change

5 The following examples for activities generating $1 \mathrm{tCO}_{2}$ were chosen: (i) a 7,200 $\mathrm{km}$ driving with a VW Lavida 1.4 TSI, (ii) the electricity consumption of one person in 870 days, and (iii) $13.2 \%$ of the annual average per capita $\mathrm{CO}_{2}$ emissions in China. 
mitigation, as marginal benefit of contributing is zero while costs are positive. Accordingly, the proportion of subjects who buy certificates, $p^{\text {cert }}$, is zero. However, there is considerable empirical evidence from previous revealed preferences studies (Löschel et al. 2013, Diederich and Goeschl 2014 2017, Uehleke and Sturm 2017) and the literature on donations (e.g. Andreoni 1990), that shows that contributions in such decision situations are positive. On the one hand, positive contributions can be explained by moral motivations, which are associated with contributing to the public good itself rather than with the effect of the contribution (Cooper et al. 2004). For example, subjects could receive a 'warm glow' of giving (Crumpler and Grossman 2008), could buy moral satisfaction instead of ascribing an economic value to the public good (Kahneman and Knetsch 1992), gain from a positive self-image (JohanssonStenman and Svedsäter 2010), or follow deontological decision rules that cause them to disregard consequences and instead decide on the basis of morally mandated duties to 'do the right thing' (Spash 2006). This behavior can be described as unconditionally cooperative. On the other hand, it is possible that some subjects are willing to contribute only under the condition that others also do so (e.g. Sugden 1984, Fischbacher et al. 2001). In our design, subjects had to build their own expectations regarding the behavior of other subjects and, consequently, only those conditionally cooperative subjects who expected that others would also "bear their share" would contribute. However, since free-riding within the group is possible, strong incentives exist to understate the demand for the public good.

Based on these considerations, we can state our first hypothesis $H 1$ regarding $p^{\text {cert }}$, the proportion of subjects who buy:

$$
\text { Hypothesis } H 1: \quad H_{0}: p_{\text {Shenzhen }}^{\text {cert }}=0 \text { vs. } H_{A}: p_{\text {Shenzhen }}^{\text {cert }}>0 .
$$

Due to the local co-benefits from climate change mitigation in Beijing, subjects in this treatment should have an additional incentive to contribute compared to treatment Shenzhen. This effect is also illustrated by our theoretical considerations in Section 2. However, also the provision of cleaner air as an example for local co-benefits represents a (local) public good and the marginal benefit of contributing is virtually zero in this decision situation. Thus, it is an empirical question whether and to what extent subjects react to the treatment effect. Therefore, we derive our second hypothesis $H 2$ :

$$
\text { Hypothesis } H 2: \quad H_{0}: p_{\text {Beijing }}^{\text {cert }}=p_{\text {Shenzhen }}^{\text {cert }} \text { vs. } H_{A}: p_{\text {Beijing }}^{\text {cert }}>p_{\text {Shenzhen }}^{\text {cert }} .
$$

\footnotetext{
6 The real costs for purchasing the $55 \mathrm{tCO}_{2}$ in April 2017 in Beijing ETS were $55 \mathrm{tCO}_{2}$ x $39.8 \mathrm{RMB} / \mathrm{tCO}=2,189$ $\mathrm{RMB}$; and the $5 \mathrm{tCO}_{2}$ in August 2017 in Shenzhen ETS were $5 \mathrm{tCO}_{2} \times 24.8 \mathrm{RMB} / \mathrm{tCO}_{2}=124 \mathrm{RMB}$; totaling of 2,313 RMB.
} 
In the case that subjects contribute, we nevertheless would expect that the "law of demand" holds, i.e. the price should have a negative effect of the proportion of subjects who buy. This is our third hypothesis $H 3$, which holds for both treatments:

Hypothesis $H 3: \quad H_{0}$ : no price effect on $p^{\text {cert }}$ vs. $H_{A}: p^{\text {cert }}$ decreases with price.

\section{Results}

\subsection{Pool of participants and their environmental attitudes}

Tables A3_3a-3k in Appendix 3 present the participants' socio-economic characteristics. Our subject pool covers all age groups from 18-75 years for men as well as for women. The sample is, however, characterized by an underrepresentation of male subjects in general and subjects in the age group 40-49 years. Furthermore, subjects with higher education (undergraduate or higher) are overrepresented in our sample. ${ }^{7}$

Table A3_1b in Appendix 3 presents participants' attitudes towards climate change (see also Table 7). $39 \%$ of our subjects are concerned about human-induced climate change. Meanwhile, $75 \%$ of the sample are concerned about local air pollution caused by pollutants in the north (incl. Beijing) but only $18 \%$ are concerned about local air pollution caused by pollutants in the south (incl. Shenzhen). There is a statistically significant difference between the concern about local air pollution in the north (incl. Beijing) and in the south (incl. Shenzhen) (Wilcoxon matched pairs test, $\mathrm{p}$-value $<0.001$ ).

\subsection{Univariate analysis of the treatment effect}

In a first step, we compare individual behavior in the treatments Beijing and Shenzhen by defining two types: (i) Subjects do not buy for any price ("no contribution" - noC), and (ii) subjects buy for at least one price ("contribution"-C). Based on the distribution of types (see Figure 2), we can state that in both treatments the proportion of C-types is clearly above zero. Furthermore, the increase in C-types from $44 \%$ in Shenzhen to $64 \%$ in Beijing is significant (exact Fisher test, p-value $=0.001$ ). Thus, we can reject our null hypotheses in $H 1$ and $H 2$.

7 All comparisons concerning representativeness are based on Chi2 tests with $p<0.05$ level of significance. The population of the city of Beijing (census data from 2010) is the population of interest. 


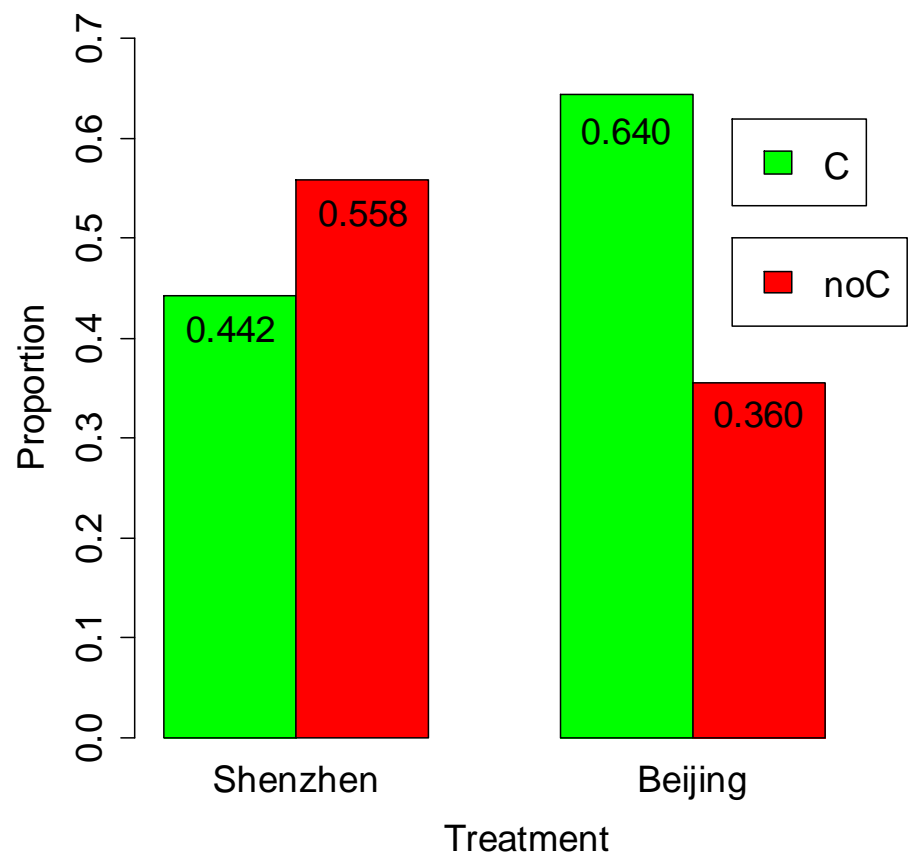

Figure 2: Types in treatments Beijing and Shenzhen

In the next step, we analyze subjects' implicit willingness to pay (WTP). For this purpose we denote the highest price a subject $i$ is willing to accept as minimum WTP $\left(W T P_{\min }\right)$. For subjects who do not buy at any price we set $W T P_{\min }=0 .{ }^{8}$

Table 4: $W T P_{\min }$ for treatments Beijing and Shenzhen

\begin{tabular}{lccccccc}
\hline in RMB & Min & $Q_{1}$ & Median & Mean & $Q_{3}$ & Max & $\mathrm{n}$ \\
\hline Beijing & 0.00 & 0.00 & 5.00 & 12.35 & 14.00 & 300.00 & 211 \\
Shenzhen & 0.00 & 0.00 & 0.00 & 13.03 & 9.00 & 300.00 & 93 \\
\hline
\end{tabular}

The descriptive statistics for $W T P_{\text {min }}$ are shown in Table 4 . While the median $W T P_{\text {min }}$ in treatment Beijing is $5 \mathrm{RMB}$, it is $0 \mathrm{RMB}$ in Shenzhen. This difference is also significant (twosided MWU test, $\mathrm{p}$-value $=0.0199$ ). There is no difference regarding the mean $W T P_{\min }$ (twosided t-test, $\mathrm{p}$-value $=0.874$ ). This result shows that for small prices, i.e. in the range $[2,5]$, the change of the treatment from Shenzhen to Beijing has a positive effect on the WTP. To put it another way, the median WTP for permits is completely determined by the preference for local co-benefits of $\mathrm{CO}_{2}$ emissions reduction.

8 Subjects who do not behave in an economically consistent manner, i.e. who have a partially increasing demand function (4\%), are excluded from this analysis. 


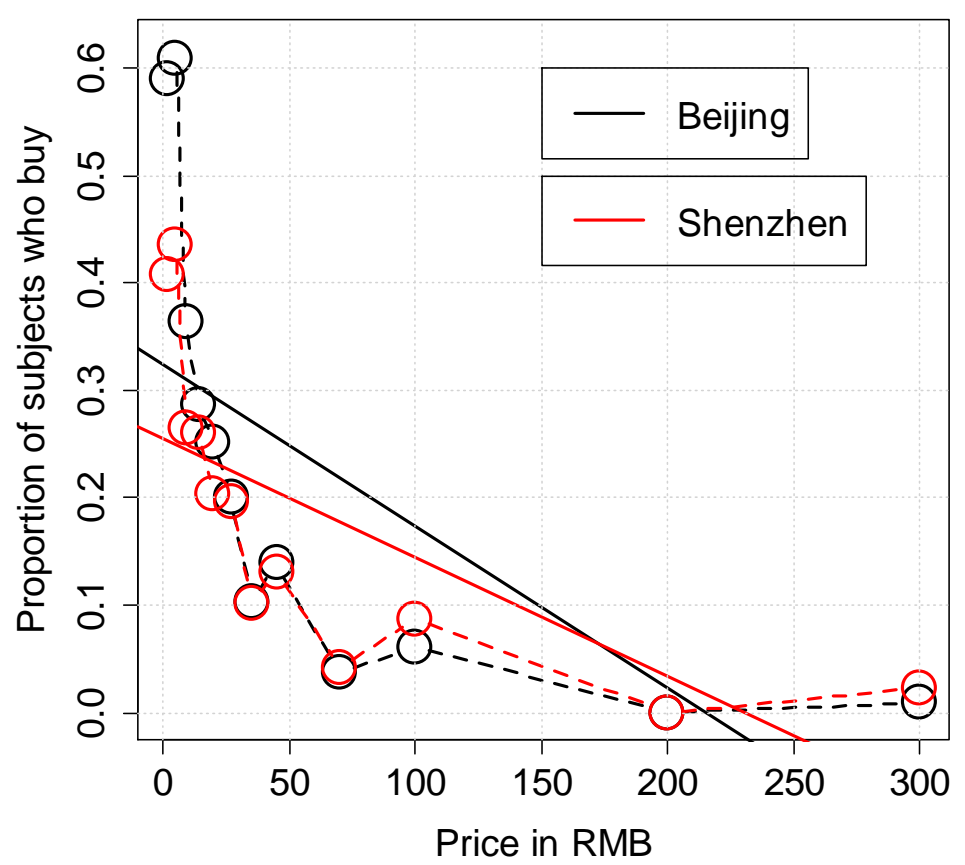

Figure 3: Price and proportion of subjects who buy for treatments Beijing and Shenzhen

In the third step, we calculate the share of buyers of certificates, $p_{\text {treatment }}^{\text {cert }}$, per price in each treatment. Figure 3 shows for both treatments, Beijing and Shenzhen, the proportion of subjects who buy, i.e. $p_{\text {Beijing }}^{\text {cert }}$ and $p_{\text {Shenzhen }}^{\text {cert }}$, for each of the 12 different prices. The demand curves do not decrease monotonically, but the fitted values show a clear downward trend as prices increase. The difference in proportions between both treatments is quite large for low prices, in particular for the price range $[2,5]$. Here, the proportion of subjects who buy in treatment Beijing is about 20 percentage points higher than in Shenzhen. For larger prices, i.e. the range $[9,300]$, the demand curves overlap for many prices, suggesting that the treatment effect is only valid for low prices. In general, the proportion of subjects who buy for prices above $45 \mathrm{RMB}$ is quite low in both treatments.

We test the null hypothesis of independence between the purchase decision in Beijing and Shenzhen with the Fisher exact test for count data (see Table 5). For all prices in Beijing in $22.1 \%$ of all cases subjects purchase certificates compared to $17.9 \%$ in Shenzhen (p-value = 0.042). Testing at the individual price level leads to a differentiated picture. For the smallest price of both price vectors we can reject the null hypothesis at least at a $10 \%$ level of significance (at $P=2$ with $\mathrm{p}$-value $=0.040$ and at $P=5$ with $\mathrm{p}$-value $=0.054$ ). Thus, there is weak statistical evidence that for low prices in the range $[2,5]$ subjects purchase permits more often in Beijing than in Shenzhen. For [9, 300] there are no significant effects. Since observations for $P=2$ and $P=5$ are independent, we can jointly test whether the null hypothesis of independence between the purchase decision in Beijing and Shenzhen can be 
rejected. From the 173 purchase decisions in this price range $133(76.9 \%)$ took place in Beijing and $40(23.1 \%)$ in Shenzhen. Of the 144 no-buy-decisions 89 (61.8\%) occurred in Beijing and $55(38.2 \%)$ in Shenzhen. For both prices, the null hypothesis of independence between the purchase decision in Beijing and Shenzhen can be rejected at a p-value $=0.004$ (Fisher exact test).

Table 5: Proportion of subjects who buy for treatments Beijing and Shenzhen

\begin{tabular}{cccccc}
\hline$P$ & $p_{\text {Beijing }}^{\text {cert }}$ & $n$ & $p_{\text {Shenzhen }}^{\text {cert }}$ & $n$ & $\mathrm{p}$-value \\
\hline 2 & 0.589 & 107 & 0.408 & 49 & 0.040 \\
5 & 0.609 & 115 & 0.435 & 46 & 0.054 \\
9 & 0.364 & 107 & 0.265 & 49 & 0.273 \\
14 & 0.287 & 115 & 0.261 & 46 & 0.847 \\
20 & 0.252 & 107 & 0.204 & 49 & 0.550 \\
27 & 0.200 & 115 & 0.196 & 46 & 1 \\
35 & 0.103 & 107 & 0.102 & 49 & 1 \\
45 & 0.139 & 115 & 0.130 & 46 & 1 \\
70 & 0.037 & 107 & 0.041 & 49 & 1 \\
100 & 0.061 & 115 & 0.087 & 46 & 0.512 \\
200 & 0.000 & 107 & 0.000 & 49 & NA \\
300 & 0.009 & 115 & 0.022 & 46 & 0.491 \\
\hline Total & 0.221 & 1332 & 0.179 & 570 & 0.042 \\
\hline
\end{tabular}

Note: Two-sided Fisher exact test for count data.

Thus, we can summarize that the proportion of subjects who buy is positive for almost all prices and quickly decreases with price. Null hypotheses in $H 1$ and $H 3$ therefore must be rejected. Furthermore, in the price range $[2,5]$ the proportion of subjects who buy is significantly higher in Beijing than in Shenzhen, meaning that the null hypothesis in $H 2$ is rejected for low prices.

In both treatments, Beijing and Shenzhen, we asked subjects at each price about their expectations regarding the share of all other participants they believed would purchase the permit at the respective price levels. ${ }^{9}$ Figure 4 shows that the mean percentage of individual expectations in Beijing ( $\operatorname{Exp}_{\text {Beijing }}$ ) is constantly above the mean in Shenzhen $\left(\operatorname{Exp}_{\text {Shenzhen }}\right) .{ }^{10}$ Furthermore, mean expectations decrease with price.

9 In treatment Beijing, subjects who faced a second decision situation where not asked about their expectations. $10 \mathrm{We}$ also asked subjects about their ETS price expectations (see Appendix 3, Table A3_2a). There is no significant difference in the ETS price expectations between both regions (MWU test, p-value $=0.733$ ). Furthermore, $80 \%(79 \%)$ of subjects in the Beijing (Shenzhen) treatment indicated that they do not know the ETS price (see A3_2a in Appendix 3). Due to this observation and the fact that private access to the Chinese ETS markets is to our knowledge practically impossible, we can assume that field prices did not affect individual purchase decisions in our experiment. 


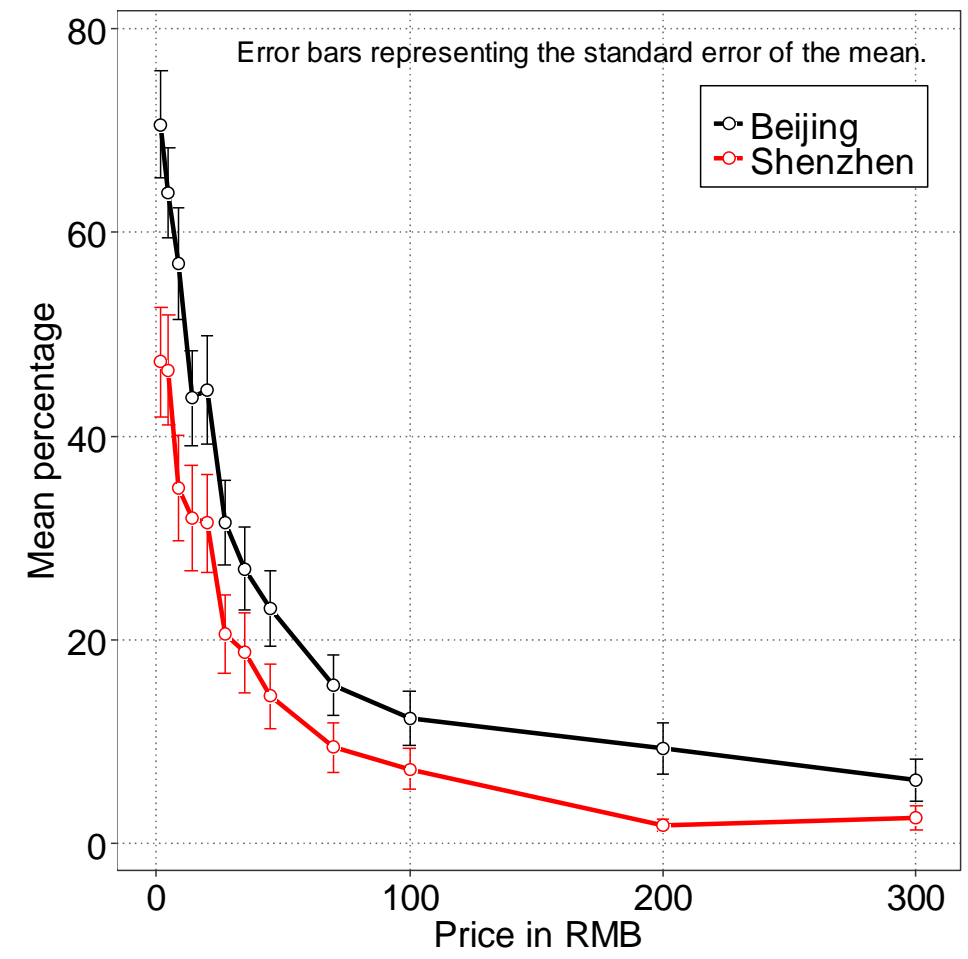

Figure 4: Expectations regarding the percentage of other subjects who buy

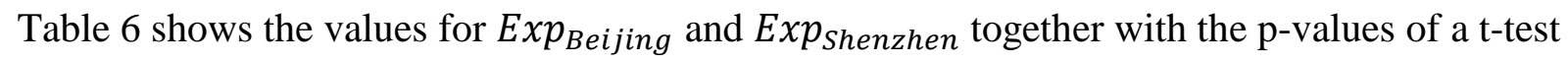
for each price $P$. For the price range [2,9] mean expectations in Beijing are significantly higher than in Shenzhen at a p-value $<0.05$. The price range broadens to $[2,27]$ if we accept a $10 \%$ level of significance.

Table 6: Expectations regarding the percentage of other subjects who buy

\begin{tabular}{cccccc}
\hline$P$ & Exp $_{\text {Beijing }}$ & Exp $_{\text {Shenzhen }}$ & $\mathrm{t}$-value & $\mathrm{df}$ & $\mathrm{p}$-value \\
\hline 2 & 70.61 & 47.28 & -3.09 & 93.00 & 0.003 \\
5 & 63.89 & 46.52 & -2.49 & 91.16 & 0.015 \\
9 & 57.02 & 34.96 & -2.93 & 92.27 & 0.004 \\
14 & 43.72 & 31.91 & -1.71 & 94.45 & 0.091 \\
20 & 44.57 & 31.45 & -1.83 & 91.64 & 0.071 \\
27 & 31.50 & 20.54 & -1.93 & 97.97 & 0.057 \\
35 & 26.98 & 18.70 & -1.47 & 92.46 & 0.144 \\
45 & 23.06 & 14.41 & -1.77 & 97.72 & 0.080 \\
70 & 15.48 & 9.41 & -1.58 & 89.53 & 0.117 \\
100 & 12.30 & 7.26 & -1.53 & 94.55 & 0.130 \\
200 & 9.26 & 1.75 & -2.92 & 50.85 & 0.005 \\
300 & 6.24 & 2.46 & -1.59 & 83.29 & 0.116 \\
\hline
\end{tabular}

Note: Two-sided t-test.

\subsection{Econometric analysis}

This section presents logit models to estimate treatment and covariate effects on the probability to buy the certificate. Therein, the purchase of certificate (yes/no) is the dependent variable. Table 7 summarizes the socio-economic covariates of the following models. The 
covariates contain standard demographic variables such as gender, age, income, and academic education. We also include dummy variables for religion and risk preference, membership to the communist party as well as for having children below 6 years and between 6 and 18 years. Furthermore, commuting time is also included. Additionally, we control for individual attitudes towards the environment and climate policies. $39 \%$ of respondents are concerned about global warming. 75\% (18\%) are concerned about pollution in the north incl. Beijing (south incl. Shenzhen). $22 \%$ of respondents agree with the statement "It is pointless to try to do something against climate change as an individual." We use this statement as a proxy for dilemma awareness, which measures the degree to which the sample is aware of the social dilemma of emissions reductions as dilemma awareness has been found to affect WTP for public goods (Liebe et al. 2011, Uehleke and Sturm 2017). We measure the degree of proenvironmental behavior with the Personal Norm Scale (Stern et al. 1999, Steg et al. 2005, Steg et al. 2013) which explains support for pro-environmental action. The question wording and the scale properties are given in Appendix 3 (Table A3_3e). Finally, 42\% stated that they trust that the ETS is fit to reduce $\mathrm{CO}_{2}$ emissions.

The results for the logit models are presented in Table 8 in which coefficients are presented as odds ratios. Model 1 includes only the price $P$ as an explanatory variable. Model 2 adds a dummy variable for the Beijing treatment (the reference is Shenzhen in this case). In model 3 an interaction dummy variable for Beijing and prices in [2, 5] is added. Model 4 adds socioeconomic characteristics and various environmental attitudes. ${ }^{11}$ Overall, the logit results confirm the univariate results of the treatment influence, meaning that we have to reject the null in $\mathrm{H} 2$ and in $\mathrm{H} 3$ for low prices. For prices in $[2,5]$, the odds ratio of being in the Beijing group over being in the Shenzhen group is 4.25 , indicating that the odds of buying a certificate are 3.25 times higher in the Beijing group than in Shenzhen group for this price interval, when all other variables remain constant.

11 Models 5-7 (see Appendix 4) include interaction terms between the Beijing treatment condition and a dummy for prices in [2, 14], [2, 27] and [2, 45]. Due to the higher goodness-of-fit measure we focus here on model 4. Model 4 is also estimated with a random effects (RE) structure (see Appendix 4, model 4 RE). We refer only to the clustered standard errors model here since the model fit for this model is much better than for the random effects model (see Figure 5 in Appendix 4). 
Table 7: Summary of socio-economic covariates

\begin{tabular}{lrrrr}
\hline Variable & Mean & Std.Dev. & Min & Max \\
\hline Female & 0.64 & 0.48 & 0 & 1 \\
Age (in years) & 41.23 & 14.63 & 19 & 77 \\
Income (in 1,000 RMB) & 6.50 & 4.87 & 0.50 & 25.00 \\
Academic degree & 0.58 & 0.49 & 0 & 1 \\
Religion & 0.09 & 0.28 & 0 & 1 \\
Risk (in [1,10]) & 4.93 & 2.34 & 1 & 10 \\
Party & 0.32 & 0.47 & 0 & 1 \\
Children between 6 and 18 years & 0.08 & 0.28 & 0 & 1 \\
Children below 6 years & 0.18 & 0.38 & 0 & 1 \\
Commuting time (in hours) & 1.36 & 0.78 & 0.25 & 3.25 \\
Concern for climate change & 0.39 & 0.49 & 0 & 1 \\
Concern pollution (north) & 0.75 & 0.43 & 0 & 1 \\
Concern pollution (south) & 0.18 & 0.39 & 0 & 1 \\
Dilemma awareness & 0.22 & 0.42 & 0 & 1 \\
Personal norm (in [1,4]) & 2.99 & 0.49 & 1.40 & 4.00 \\
Trust in ETS & 0.42 & 0.49 & 0 & 1 \\
\hline
\end{tabular}

Furthermore, in model 4 we find evidence for the factors underlying the decision (ceterisparibus for $\mathrm{p}$-value $<0.05)$. First, for individual decisions the price $P$ of the certificate reduces the odds of buying by $3 \%$ for each additional RMB. Second, increasing individual risk attitude has a positive effect on the purchase probability. With each additional point on the risk scale the odds of buying increases by $26 \%$. Subjects who trust in the ETS have 1.74 times higher odds in making a transaction than subjects who do not trust in the ETS. Furthermore, subjects who identified themselves as religious exhibit 1.19 times higher odds than nonreligious subjects of purchasing certificates. Finally, subjects with children aged between 6 and 18 years have $70 \%$ smaller odds of buying than subjects not in this group.

The results of our regression analysis (model 4) can be supported by literature on the issue. The observed effects for price and trust in ETS are qualitatively consistent with similar studies executed with EU ETS permits (e.g. Uehleke and Sturm 2017). Meanwhile, the empirical evidence regarding the effect of risk attitude on contributions to environmental goods is limited. Contrary to our results, Bartczak et al. (2016) find that risk seekers contribute less to the local environmental good species protection. Given the literature, the insignificance of effects for the variables dilemma awareness and personal norm as well as the environmental concern variables is surprising too. The negative effect of having older children on the purchase decision might be explained by the fact that those subjects have a tighter budget constraints. 
Table 8: Logit regression

\begin{tabular}{|c|c|c|c|c|}
\hline & Model 1 & Model 2 & Model 3 & Model 4 \\
\hline P (in RMB) & $0.97(0.01)^{* * *}$ & $0.97(0.01)^{* * *}$ & $0.98(0.01)^{* * *}$ & $0.97(0.01)^{* * * *}$ \\
\hline Beijing & & $1.36(0.32)$ & & \\
\hline BeijingxP.eol.5 & & & $3.08(0.75)^{* * *}$ & $4.25(1.31)^{* * *}$ \\
\hline BeijingxP.larger.5 & & & $0.97(0.24)$ & $0.95(0.28)$ \\
\hline Female & & & & $0.79(0.22)$ \\
\hline Age & & & & $0.97(0.01)$ \\
\hline Income & & & & $1.03(0.03)$ \\
\hline Academic.degree & & & & $1.85(0.79)$ \\
\hline Commuting.time & & & & $1.02(0.15)$ \\
\hline Religion & & & & $2.19(0.83)^{*}$ \\
\hline Risk & & & & $1.26(0.07)^{* * *}$ \\
\hline Party & & & & $1.36(0.34)$ \\
\hline Children.between.6.18 & & & & $0.30(0.16)^{*}$ \\
\hline Children.below.6 & & & & $0.90(0.30)$ \\
\hline Trust.in.ETS & & & & $2.74(0.67)^{* * *}$ \\
\hline Dilemma.awareness & & & & $0.88(0.33)$ \\
\hline Personal.norm & & & & $0.82(0.25)$ \\
\hline Concern.climate.change & & & & $0.97(0.26)$ \\
\hline Concern.pollution.north & & & & $1.12(0.35)$ \\
\hline Concern.pollution.south & & & & $1.12(0.40)$ \\
\hline Num. obs. & 1902 & 1902 & 1902 & 1543 \\
\hline Pseudo R2 & 0.171 & 0.174 & 0.195 & 0.328 \\
\hline
\end{tabular}

Notes: ${ }^{* * *} \mathrm{p}<0.001,{ }^{* * *} \mathrm{p}<0.01,{ }^{*} \mathrm{p}<0.05$. Purchase of certificate (yes/no) is the dependent variable, coefficients are presented as odds ratios, standard errors in parentheses are corrected for clustered observations. "eol.5" = equal or lower $5 \mathrm{RMB}$.

To illustrate the identified effects in Table 9 average marginal effects on the probability to buy are presented. For the price range $[2,5]$ in the Beijing treatment, for example, subjects on average have a 16 percentage points higher probability to purchase a certificate than in the Shenzhen treatment.

Table 9: Average marginal effects on the probability to buy

\begin{tabular}{lrcrc}
\hline & $d F / d x$ & $S E$ & \multicolumn{1}{c}{$Z$} & $P>|z|$ \\
\hline P (in RMB) & -0.0031 & 0.0007 & -4.50 & 0.000 \\
BeijingxP.eol.5 & 0.1607 & 0.0339 & 4.74 & 0.000 \\
Religion & 0.0870 & 0.0415 & 2.10 & 0.036 \\
Risk & 0.0260 & 0.0064 & 4.09 & 0.000 \\
Children.between.6.18 & -0.1321 & 0.0569 & -2.32 & 0.020 \\
Trust.in.ETS & 0.1121 & 0.0258 & 4.35 & 0.000 \\
\hline
\end{tabular}

Notes: Average marginal effects for statistically significant variables in model 4 (see Table 8). Standard errors are corrected for clustered observations.

\subsection{Elasticity}

Based on the logit estimates presented in Section 5.3 and following the analysis of Diederich and Goeschl (2017), we calculate the corresponding average marginal effects and the average elasticity of the probability of purchasing with respect to the price (LeClere 1992). The 
elasticity of the probability of purchasing captures the change in the probability to buy certificates caused by a one percent change in price and is calculated as follows

$$
\eta_{P r}=\frac{\delta \operatorname{Pr}\left(Y_{i}=1\right)}{\delta P} \frac{P}{\operatorname{Pr}\left(Y_{i}=1\right)}
$$

where $Y_{i}$ is an indicator variable that takes the value of 1 for a contributor and $\frac{\delta \operatorname{Pr}\left(Y_{i}=1\right)}{\delta P}=M E$ is the marginal effect of a price increase on the probability. An elasticity below one (in absolute value) then describes a less-than-proportionate change in the probability relative to the price $P$, and vice versa.

Table 10: Average marginal effects and elasticities

\begin{tabular}{lcccccc}
\hline & \multicolumn{2}{c}{ All observations } & \multicolumn{2}{c}{ Beijing } & \multicolumn{2}{c}{ Shenzhen } \\
\hline prices & $M E$ & $\eta_{P r}$ & $M E$ & $\eta_{P r}$ & $M E$ & $\eta_{P r}$ \\
\cline { 2 - 6 }$[2,14]$ & $-0.025^{* *}$ & $-0.510^{* *}$ & $-0.028^{* *}$ & $-0.572^{* *}$ & $-0.015^{*}$ & $-0.363^{*}$ \\
& $(0.003)$ & $(0.084)$ & $(0.004)$ & $(0.101)$ & $(0.006)$ & $(0.156)$ \\
{$[2,45]$} & $-0.011^{* *}$ & $-0.895^{* *}$ & $-0.012^{* *}$ & $-0.978^{* *}$ & $-0.008^{* *}$ & $-0.696^{* *}$ \\
& $(0.001)$ & $(0.104)$ & $(0.001)$ & $(0.130)$ & $(0.002)$ & $(0.168)$ \\
{$[2,300]$} & $-0.005^{* *}$ & $-2.241^{* *}$ & $-0.006^{* *}$ & $-2.652^{* *}$ & $-0.003^{* *}$ & $-1.473^{*}$ \\
& $(0.001)$ & $(0.430)$ & $(0.001)$ & $(0.557)$ & $(0.001)$ & $(0.580)$ \\
\hline
\end{tabular}

Notes: Average marginal effect of the price on the probability to buy $(M E)$ and average elasticity of the probability of contributing $\left(\eta_{P r}\right)$. Specification with price as the only explanatory variable (model 1 in Table 8). Standard errors in parentheses are corrected for clustered observations. ${ }^{* *} \mathrm{p}<0.01,{ }^{*} \mathrm{p}<0.05$.

In Table 10 the results are shown for the specification with the price as the only explanatory variable. ${ }^{12}$ For all observations, the absolute effect of the marginal effect ( 1 unit $\left.=1 \mathrm{RMB}\right)$ decreases across the price range. This is consistent with the purchase behavior depicted in Figure 3. A price increase by 1 RMB has a rather strong effect on the probability to buy when the price level is low compared to a broader price range including higher prices. For Beijing, the marginal effect of a price increase on the probability to buy is stronger than for Shenzhen in all price ranges. This observation is also in line with Figure 3 as the proportion of subjects who buy is much higher in Beijing than in Shenzhen at low prices while both proportions converge quickly to zero as prices increase.

Across the entire price range, the elasticity is estimated at $\eta_{P r}=-2.24$. A one percent increase in price on average leads to a decrease of the purchase probability by 2.24 percent. Thus, overall we observe an elastic price reaction. Starting from low prices in the range [2, 14] the absolute value of the elasticity increases, i.e. the price reaction becomes more elastic. This effect is caused by the observed pattern of purchase decisions (see Figure 3). For low prices in $[2,14]$ the probability to buy is in the range of $50 \%$. A $1 \%$-increase of the price 
causes an inelastic reaction in this case. For high prices the probability to buy quickly reaches values near zero. A $1 \%$-increase in the price therefore causes an elastic reaction. As expected the absolute value of the elasticity is higher in Beijing than in Shenzhen for all price ranges. Overall, the observed elasticity for Beijing is $\eta_{P r}=-2.65$ and for Shenzhen $\eta_{P r}=-1.47$.

It is interesting to note that in a similar setting Diederich and Goeschl (2017) report an elasticity of $\eta_{P r}=-0.3$ across the entire price range for a German sample. It follows from this observation, that rising prices will not matter much for the demand for voluntary $\mathrm{CO}_{2}$ reductions. In contrast to the inelastic price reaction observed in Germany, our subjects in the Shenzhen treatment, where only the public good characteristic should matter, exhibit price elastic behavior. Obviously, the demand reaction to price increases of a global public good in emerging economies such as China is much more price sensitive than in developed countries such as Germany. Assuming that prices for $\mathrm{CO}_{2}$ reductions in China will rather increase in the future than decrease, our policy conclusion is, therefore, rather pessimistic since then the potential of voluntary contributions to $\mathrm{CO}_{2}$ reductions reduces accordingly.

\subsection{Additional WTP estimates}

In order to prove the robustness of the results obtained so far, we present additional WTP estimates. To estimate the WTP from dichotomous responses we use the lower-bound Turnbull (LBT) estimator (see Turnbull 1976, Haab and McConnell 2003) which is a nonparametric estimation method. The advantage of this approach is that it relies only on the respondents' information, namely that the WTP is at least the presented price if the certificate is purchased. The calculation of the LBT estimator is explained in Appendix 5.

Table 10: WTP estimates

\begin{tabular}{|c|c|c|c|}
\hline WTP in RMB & All observations & Beijing & Shenzhen \\
\hline mean $[95 \% \mathrm{CI}]$ & $11.29[9.60,12.99]$ & $11.39[9.51,13.27]$ & $11.10[7.55,14.65]$ \\
\hline median & {$[2,9]$} & {$[2,9]$} & {$[0,2]$} \\
\hline l.i.median & 3.51 & 4.95 & 1.73 \\
\hline
\end{tabular}

The WTP estimates are shown in Table 10 for all observations as well as for both treatments Beijing and Shenzhen. The mean WTP for Beijing (11.39 RMB) is only slightly larger than for Shenzhen (11.10 RMB) and both confidence intervals clearly overlap. Additionally, due to the

12 See Appendix 4 (Table A4_2) for estimates with price and other covariates in model 4 (Table 8) which are very similar to the values presented here. 
low number of purchases at higher prices, the standard deviation is rather large (see Appendix 5) and consequently the confidence intervals are rather broad. The median which is robust to extreme observations is much lower than the mean in both treatments. The reason for this observation is that the mean for both treatments is biased to the right by a few purchases at the highest prices above 70 RMB (see Table 5 and Appendix 5). Therefore, we focus on the median here. The median is in the price range $[2,9]$ for Beijing and in $[0,2]$ for Shenzhen. According to the linearly interpolated median in Beijing 50\% of the subjects have a WTP of 4.95 RMB or more while in Shenzhen 50\% of the subjects have a WTP of only 1.73 RMB or more. Thus, we can state that based on the linearly interpolated median in Beijing $65 \%$ of the WTP for a certificate is driven by a preference for local co-benefits and $35 \%$ by a preference for reducing global warming. Obviously, the weights of the preferences for local co-benefits on the one hand and global $\mathrm{CO}_{2}$ emissions reduction on the other hand depend on the chosen metric (see our calculation in Section 5.2). Based on our results we can conclude, that regarding the median WTP the preference for local co-benefits such as the reduction of local air pollution seems to be more important than the preference to avoid global warming.

\section{Conclusion}

China, the world's largest $\mathrm{CO}_{2}$ emitter, has to struggle with severe environmental problems such as local air pollution. Due to the link between $\mathrm{CO}_{2}$ emissions and, especially, local air pollution it is often suggested that the country has additional private incentives, so called cobenefits, to contribute to $\mathrm{CO}_{2}$ reduction. In this paper, we present first experimental evidence on these co-benefits from climate change mitigation which are observable in real individual decisions. For this purpose, we use the fact that in China several sub-national emissions trading schemes (ETS) exist which are separate from each other. In our experiment, we sell permits from Beijing and Shenzhen ETS to a sample of subjects from Beijing. Both regions, Beijing and Shenzhen, are sufficiently far away from each other in order to avoid an increase of local pollution levels in Beijing caused by emissions in Shenzhen. Since $\mathrm{CO}_{2}$ emissions are inevitably linked to emissions of local air pollutants, our design allows us to separate the demand for local environmental protection on the one hand and mitigating anthropogenic global warming on the other. Our core result is that Chinese subjects have a positive demand for climate change mitigation and - at low prices only - an additional positive demand for local environmental protection as the latter generates local co-benefits, e.g., in the form of reduced air pollution. The demand reaction to the $\mathrm{CO}_{2}$ price has the expected negative sign and is relatively elastic. This elastic price reaction lowers the potential of voluntary $\mathrm{CO}_{2}$ 
reductions under rising prices. Interestingly, subjects expect the observed demand behavior regarding price and treatment effect.

Our results may partly explain China's active role in recent climate policy: China does not only benefit from mitigating climate change, but does so too from the associated local cobenefits. Two qualifications are in order regarding the policy implications of our results. First, since we measure individual demand decisions in a public good context, our individual data do not reflect the "true" demand or WTP for the provision of the public good. We can assume that the individual demand for the global public good, and thus the WTP, depend on the decision of other subjects and on the level of collective action at the national and international level. Our results, however, show that even under complete absence of collective action Chinese subjects are willing to sacrifice their own money in order to mitigate climate change and, additionally, to provide local co-benefits such as reduced air pollution. Secondly, the identified value added from local co-benefits seems to be relatively small and is limited to small prices only. However, we must also take into account that our design frames reducing $\mathrm{CO}_{2}$ emissions as a primary benefit and the reduction of local air pollution as a co-benefit only. Interestingly, even under this framing we were able to show a treatment effect. For the median WTP the preference for local environmental protection such as the reduction of local air pollution is even stronger than the preference for contributing to climate change mitigation. It might certainly be the case that the additional demand for local environmental protection is much higher when reducing $\mathrm{CO}_{2}$ emissions is treated as the side-benefit and effects such as improving local air pollution are listed as the primary benefit. Due to the massive local air pollution in Chinese cities, there are good reasons to assume that for Chinese subjects the marginal benefit from reducing local air pollution is much higher than from mitigating climate change. Thus, the effect identified in our study can be seen as "lower bound" for the true treatment effect. 


\section{Literature}

Bartczak, A., Mariel, P., Chilton, S., Meyerhoff, J. (2016): The impact of latent risk preferences on valuing the preservation of threatened lynx populations in Poland. Australian Journal of Agricultural and Resource Economics 59, 1-23

Barwick P.J., Li S., Rao D., Zahur N.B. (2017): Air Pollution, Health Spending and Willingness to Pay for Clean Air in China, Discussion Paper, July 2017.

Baumgärtner, S., Chen, W., Hussain, A.M.T. (2017): Willingness to pay for public environmental goods under uncertainty, AURÖ Young Researchers Workshop "Environmental and Resource Economics", University of Basel, Schweiz 13.15.02.2017.

Cornes R., Sandler T. (1994): The comperative static properties of the impure public good model, Journal of Public Economics 54, 403-421.

Deng, H.-M., Liang, Q.-M., Liu, L.-J., Anadon, L.D. (2017): Co-benefits of greenhouse gas mitigation: a review and classification by type, mitigation sector, and geography, Environmental Research Letters 12(12), 1-26.

Diederich J., Goeschl T. (2017): To mitigate or not to mitigate: The price elasticity of proenvironmental behavior, Journal of Environmental Economics and Management 84, 209-222.

Diederich J., Goeschl T. (2014): Willingness to pay for voluntary climate action and its determinants: field experimental evidence, Environmental and Resource Economics 57(3), 405-429.

Du G., Shin K.J., Managi S. (2016): Environment and Life Satisfaction: Evaluating the Effects of Air Pollution on Subjective Well-being in Beijing, Discussion Paper.

Ebert, U. (1993): A note on willingness to pay and willingness to accept. Social Choice and Welfare 10, 363-370.

Ebert, U. (2003): Environmental Goods and the Distribution of Income, Environmental and Resource Economics 25, 435-459.

Fischbacher U., Gächter S., Fehr E. (2001): Are people conditionally cooperative? Evidence from a public goods experiment, Economics Letters 71(3), 397-404.

Haab T.C., McConnell K.E. (2003): Valuing environmental and natural resources. The econometrics of nonmarket valuation, Edward Elgar, Cheltenham, Northampton.

Haines A. (2017): Health co-benefits of climate action, The Lancet, vol. 1, April 2017.

He G., Fan M., Zhou M. (2016): The effect of air pollution on mortality in China: Evidence from the 2008 Beijing Olympic Games, Journal of Environmental Economics and Management 79, 18-39.

HEI (2016): Burden of disease attributable to coal-burning and other major sources of air pollution in China, Health Effects Institute, August 2016, http://pubs.healtheffects.org/view.php?id=455.

Heisey P.W., Smale M., Byerlee D., Souza E. (1997): Wheat rust and the costs of genetic diversity in the Punjab of Pakistan, American Journal of Agricultural Economics, 79, 726-737.

IPCC (2014a): Annex II: Glossary [Mach, K.J., S. Planton and C. von Stechow (eds.)]. In: Climate Change 2014: Synthesis Report. Contribution of Working Groups I, II and III to the Fifth Assessment Report of the Intergovernmental Panel on Climate Change, IPCC, Geneva, Switzerland, 117-130.

IPCC (2014b): Technical Summary. Climate Change 2014: Mitigation of Climate Change. Contribution of Working Group III to the Fifth Assessment Report of the Intergovernmental Panel on Climate Change, Cambridge University Press, Cambridge, United Kingdom and New York, NY, USA. 
Jotzo, F., Löschel, A. (2014): Emissions trading in China: Emerging experiences and international lessons, Energy Policy 75, 3-8.

Johansson-Stenman O., Svedsäter H. (2012): Self-image and valuation of moral goods: stated versus actual willingness to pay, Journal of Economic Behavior and Organization 84(3), 879-891.

Kahneman D., Knetsch J.L. (1992): Valuing public goods: the purchase of moral satisfaction, Journal of Environmental Economics and Management 22(1), 57-70.

Kotchen M., Moore M.R. (2007): Private provision of environmental public goods: Household participation in green-electricity programs, Journal of Environmental Economics and Management 53, 1-16.

LeClere M.J. (1992): The interpretation of coefficients in models with qualitative dependent variables, Decision Science 23(3), 770-776.

Liebe U., Preisendörfer P., Meierhoff J. (2011): To pay or not to pay: Competing theories to explain individuals' willingness to pay for public environmental goods, Environmental Behavior 43(1), 106-130.

Löschel A., Sturm B., Vogt C. (2013): The demand for climate change mitigation - an empirical assessment for Germany, Economics Letters 118, 415-418.

Löschel A., Sturm B., Uehleke R. (2017): Revealed preferences for climate change mitigation when the purely individual perspective is relaxed - evidence from a framed field experiment, Journal of Behavioral and Experimental Economics 67, 149-160.

Midler E., Pascual U., Drucker A.G., Narloch U., Soto J.L. (2015): Unraveling the effects of payments for ecosystem services on motivations for collective action, Ecological Economics, 394-405.

Munro A., Valente M. (2016): Green goods: Are they good or bad news for the environment? Evidence from a laboratory experiment on impure public goods, Environmental and Resource Economics 65, 317-335.

Posnett J., Sandler T. (1986): Joint supply and the finance of charitable activity, Public Finance Quarterly 14(2), 209-222.

Rübbelke D.T.G. (2003): An analysis of different abatement incentives, Resource and Energy Economics 25, 269-294.

Steg L., van den Berg A.E., De Groot J.I.M. (2013): Environmental psychology. An introduction, Wiley-Blackwell, Chichester.

Steg L., Dreijerink L., Abrahamse W. (2005): Factors influencing the acceptability of energy policies: a test of VBN theory, Journal of Environmental Psychology 25(4), 415-425.

Stern P.C., Dietz T., Abel T., Guagnano G.G., Kalof L. (1999): A value-belief-norm theory of support for social movements: The case of environmentalism, Human Ecology Review 6(2), 81-97.

Sun, Y.L., Wang, Z. F., Du, W., Zhang, Q., Wang, Q.Q., Fu, P.Q., Pan, X.L., Li, J., Jayne, J., Worsnop, D. R. (2015): Long-term real-time measurements of aerosol particle composition in Beijing, China: seasonal variations, meteorological effects, and source analysis, Atmospheric Chemistry and Physics 15, 10149-10165.

Turnbull B. (1976): The empirical distribution function with arbitrarily grouped, censored and truncated data, Journal of the Royal Statistical Society B 38, 290-295.

Uehleke R., Sturm B. (2017): The influence of collective action on the demand for voluntary climate change mitigation in hypothetical and real situations, Environmental and Resource Economics 67(3), 429-454.

van der A R.J., Mijling B., Ding J., Koukouli M.E., Liu F., Li Q., Mao H., Theys N. (2016): Cleaning up the air: Effectiveness of air quality policy for $\mathrm{SO}_{2}$ and $\mathrm{NO}_{\mathrm{x}}$ emissions in China, Atmospheric Chemistry and Physics, under review.

WHO (2016): Ambient Air Pollution Database, WHO, May 2016. 
Zhang J., Wang Z., Du X. (2017a): Lessons Learned from China's Regional Carbon Market Pilots, Economics of Energy and Environmental Policy 6(2), 1-20.

Zhang X., Zhang X., Chen X. (2017b): Happiness in the air: How does a dirty sky affect mental health and subjective well-being? Journal of Environmental Economics and Management 85, 81-94. 


\section{Appendix 1: Sampling and Grouping}

\section{Sampling}

In order to have representative sample of Beijing local residents, the sampling procedure design is based on the following facts.

1) according to the population density distribution data from Beijing Statistical Agency, over $50 \%$ of the total citizens in Beijing live within the $5^{\text {th }}$ ring road, in the six districts namely Dongcheng, Xicheng, Chaoyang, Haidian, Fengtai and Shijingshan.

2) the neighborhood committee (jvweihui, introduction can be found in this Appendix below) was used as the targeted spot and communication hub. There are 1,500 neighborhood committees within the total sample, consisting of over 330 thousand households (details about each committee are purchased from a consulting company).

3) In order to minimize the cost, we use the clustering method to send invitations: a. randomly select 100 neighborhood committees (controlling for size); b. for each neighborhood committee, choose randomly of the building and the corridor (adjusted for size); c. for chosen corridor, send invitation letters one household by another (i.e., survey-type in the last step).

4) before the formal delivery, the research team carried a trial delivery of 100 invitations in the randomly selected neighborhood committees, and got 3 feedbacks, which indicated the appropriate feedback rate was about $3 \%$. In order that we get enough respondents (say, 200300) and taking into account relatively low feedback rate, 8,000 households are selected. ${ }^{13}$

\section{Grouping}

After a 6-day delivery of 8,000 invitation letters, and a careful selection of the participants, we got 317 registered subjects for our eleven sessions (see Invitation letter and the timetable of sessions in next section of this Appendix), with $64 \%$ of female and average age of 41 years-old (and the median is 36 years-old). The average size of each session is 28 .

\section{Invitation letter}

For randomly chosen household in the municipal area of Beijing

Subject: Invitation to a scientific study with payment

\section{Dear Madam/Sir,}

University of International Business and Economics (UIBE) in Beijing is a top-ranking University in China, which carries out research activities such as applied economic research. At the moment, UIBE is conducting a scientific study for which we are looking for participants. For this purpose we want to invite you.

For the participation in a study, which takes approximately 60-90 minutes, you get paid out $300 \mathrm{RMB}$ in cash. Within the study you have the opportunity to make buying decisions. For the buying decision rules are in force, which are established by the staff of the UIBE as well as the group of participants. You can take home - depending on your buying decisions as well as the buying decisions of the other participants - up to 300 RMB. Only the team of scientists get to know your identity, whereas your data are treated strictly confidential and in compliance with the data privacy act. Money amount, which you possibly paid for your purchase, are paid at the end of the study.

Please take into consideration the following prerequisites for taking part in the study:

- Enrollment by phone or email,

- Residence in Beijing (Proof, e.g. ID),

- Native Chinese,

- $\quad$ Age between 18 and 75,

13 Dr. Fred Engst and Dr. Hongyu Pan are gratefully acknowledged for their help with the developing of the sampling method. Thanks also go to Wenzhan Li, Yongjie Liu, Jiatong Jiang, Zhuqi Shen, Linshu Wang, Shuai Wang, and Jiawei Zhang for their dedicated work sending out the invitation letters, receiving phone calls/emails and related assistance. Further, we use the Wechat as a dissemination tool to call for more participants, and 1/4 to $1 / 3$ subjects are enrolled through this channel. 
- On time appearance at the chosen appointment and present this letter and your ID.

For the case that you want to take part in this study and you fulfill the above-named prerequisites, we ask you to choose one of the appointments on the back page and to enroll by phone. It is also possible to contact us by using the email address GLCE@uibe.edu.cn. Afterwards, we get in touch with you. The selection of the participants is according to scientific criteria. The study is conducted at the UIBE in Beijing. We are available for further questions by calling the phone number 010-64494361 between Feb. 17 and Feb. 25, 2017 (Monday to Friday from 13:00-17:00) as well as by email.

We would be pleased to welcome you to our study.

Yours truly,

Appointment (Weekday/Weekends, date, time)

\begin{tabular}{l|l|l|l|l} 
& Morning & \multicolumn{2}{l|}{ Afternoon } & Evening \\
\hline 11 March (Sat.) & $10: 00-11: 30$ & $1: 00-2: 30$ & $3: 00-4: 30$ & $6: 00-7: 30$ \\
\hline 12 March (Sun.) & $10: 00-11: 30$ & $1: 00-2: 30$ & $3: 00-4: 30$ & $6: 00-7: 30$ \\
\hline 13 March (Mon.) & $10: 00-11: 30$ & & $3: 00-4: 30$ & \\
\hline
\end{tabular}

\section{Enrollment:}

Please call the number 010-64494361 between 1:00 and 5:00 pm during the weekdays from Feb. 17 to Feb. 25, 2017 (Monday to Friday) or enroll via sending email to the address GLCE@uibe.edu.cn. Please name an appointment (see above) at which you want take part at the study. Your name is written down during the enrollment process - however, as stated above it is not published or passed on a third party. Please note that you cannot claim to participate at the study by with the receipt of this letter. The selection of the participants is according to scientific criteria.

\section{The location of UIBE}

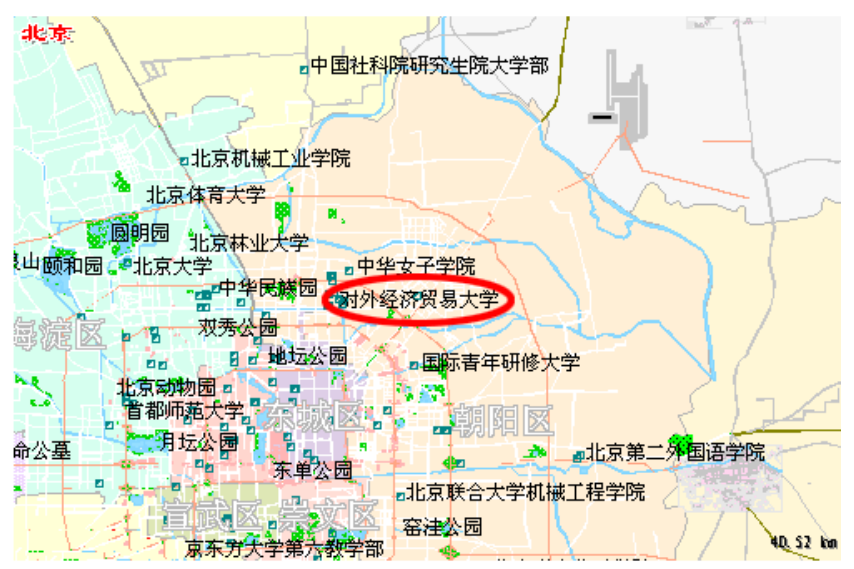

UIBE locates between $3^{\text {rd }}$ and $4^{\text {th }}$ Ring in Northeast Beijing, with China Daily to its west, China-Japan Friendship Hospital to its south, Sinopec to its north, and Shaoyaoju to its east. Many bus lines pass the west gate of UIBE, such as line 62 , line 409 , line 807, line 422, line 847, line 406, line 713, line 419, line 361, line 18, and line 379, among others. Alternatively, one can take subway line 5 or line 10 and get off at Huixinxijie Nankou Station, and using the exit B or C and another 15min walking to UIBE; or line 10 or line 13 and get off at Shaoyaoju Station, and taking exit B or A, then 10min walking to UIBE.

\section{Information about UIBE}

The University of International Business and Economics (UIBE), founded in 1951, is a multidisciplinary and national key university with economics, management, law, literature and science as its core academic areas of expertise. Since its foundation, UIBE has been steadfast in living up to its motto of "Erudition, Honesty, Endeavor and Perfection" through constant diligence and innovation.

At present, UIBE consists of 15 academic schools, a Graduate School, a Department of Physical Education and a Department of Culture and Art, offering over 1405 undergraduate courses, 875 postgraduate courses, and 109 doctoral courses. 
UIBE plays a leading role in the development of international alliance with universities around the world. Currently, UIBE has established partnerships with over 160 overseas universities and international organizations. You will find additional information about UIBE on our homepage http://www.uibe.edu.cn.

\section{Introduction of Juweihui}

The neighborhood committees or the resident committees — aka juweihui（居委会） - arose as "autonomous urban grassroots civil organizations" in the 1950s. The first neighborhood committees were found in the urban area and then in rural area of China in 1980s. Juweihui are the lowest level of government in charge of civil affairs. They help the government to enforce such policies as family planning, mobile population management, crime prevention and census administration.

Nowadays, juweihui also undertake tasks such as organizing free hobby classes; coordinating secondhand exchange markets; removing illegal advertisements; ensuring sanitation; and organizing volunteers to care for the elderly and those living with physical or mental disabilities. One of their important responsibilities is to distribute social security and welfare to low-income households, people with disabilities and the unemployed.

Normally, each juweihui is responsible for 100-700 families in the neighborhood. There are 2,932 juweihui in Beijing, according to the data released in 2015.

\section{Letter of understanding}

Thanks for your support and participation in the research conducted by the University of International Business and Economics, which is funded by the National Natural Science Foundation of China and other research grants. Please read the following carefully before you participate in the study. If you have any questions, please contact our staff.

The study lasts about 1-1.5 hours. During the course of the study, you will need to complete the survey questionnaire and make a voluntary decision based on the rule setting out in the research. Our findings will be based on your consumer decision and final payment behavior. Throughout the research process, all your decisions are made on a voluntary basis. Your personal information and decision data will be kept strictly confidential.

We will provide $300 \mathrm{RMB}$ of research subsidies for the related expenses such as the transportation expenses you are involved in.

Thanks again for your support and participation!

I have read this letter and have understood the terms of the study, and I voluntarily participate in the study regarding consumer decision making and will complete the questionnaire.

Signature of the participant: University of International Business and Economics

Date: 


\section{Appendix 2: Instructions and questionnaires}

Welcome at UIBE!

We are looking forward to your participation in our survey. Your opinion and personal assessment of a number of issues in consumption behavior is very important for us. Thank you in advance for your cooperation.

In this document you find all necessary information for the event. During the event you can go back in the document at any time.

Do not go ahead when you see the STOP sign! Please turn over this page only when we tell you to do so. Please read the instructions carefully. Do not talk to other participants.

We promise that your individual information is treated confidential.

\section{Questionnaire I}

Please answer to the following questions.

(If necessary variables and/or numeric codes are marked.)

\section{A01}

Taking all things together, how happy are you these days? Please tick a box on the scale, where the value 1 means: 'not at all happy' and the value 10 means: 'very happy'.

\begin{tabular}{|c|c|c|c|c|c|c|c|c|c|}
\hline 1 & 2 & 3 & 4 & 5 & 6 & 7 & 8 & 9 & 10 \\
\hline$\bigcirc$ & $\bigcirc$ & $\bigcirc$ & $\bigcirc$ & $\bigcirc$ & $\bigcirc$ & $\bigcirc$ & $\bigcirc$ & $\bigcirc$ & $\bigcirc$ \\
\hline
\end{tabular}

\section{A02}

All in all, how would you describe your state of health these days? Please tick a box on the scale, where the value 1 means: 'poor' and the value 10 means: 'very good'.

\begin{tabular}{|c|c|c|c|c|c|c|c|c|c|}
\hline 1 & 2 & 3 & 4 & 5 & 6 & 7 & 8 & 9 & 10 \\
\hline$\bigcirc$ & $\bigcirc$ & $\bigcirc$ & $\bigcirc$ & $\bigcirc$ & $\bigcirc$ & $\bigcirc$ & $\bigcirc$ & $\bigcirc$ & $\bigcirc$ \\
\hline
\end{tabular}

\section{A03}

All things considered, how satisfied are you with your life as a whole these days? Please tick a box on the scale, where the value 1 means: 'completely dissatisfied' and the value 10 means: 'completely satisfied'.

\begin{tabular}{|c|c|c|c|c|c|c|c|c|c|}
\hline 1 & 2 & 3 & 4 & 5 & 6 & 7 & 8 & 9 & 10 \\
\hline$\bigcirc$ & $\bigcirc$ & $\bigcirc$ & $\bigcirc$ & $\bigcirc$ & $\bigcirc$ & $\bigcirc$ & $\bigcirc$ & $\bigcirc$ & $\bigcirc$ \\
\hline
\end{tabular}

\section{A04}

Are you generally a person who is fully prepared to take risks or do you try to avoid taking risks? Please tick a box on the scale, where the value 1 means: 'unwilling to take risks' and the value 10 means: 'fully prepared to take risks'.

\begin{tabular}{|c|c|c|c|c|c|c|c|c|c|}
\hline 1 & 2 & 3 & 4 & 5 & 6 & 7 & 8 & 9 & 10 \\
\hline$\bigcirc$ & $\bigcirc$ & $\bigcirc$ & $\bigcirc$ & $\bigcirc$ & $\bigcirc$ & $\bigcirc$ & $\bigcirc$ & $\bigcirc$ & $\bigcirc$ \\
\hline
\end{tabular}

A05

Are you generally concerned about human-induced climate change?

\begin{tabular}{|c|c|c|c|}
\hline $\begin{array}{c}\text { Not concerned } \\
1\end{array}$ & $\begin{array}{c}\text { Rather not } \\
\text { concerned 2 }\end{array}$ & $\begin{array}{c}\text { Rather concerned } \\
\text { Concerned }\end{array}$ & 4 \\
\hline$\bigcirc$ & $\bigcirc$ & $\bigcirc$ & $\bigcirc$ \\
\hline
\end{tabular}




\section{A06}

Are you generally concerned about local air pollution caused by pollutants like for example particulate matter (PM2.5 and PM10), sulfur dioxide, nitrogen dioxide or ozone?

Please tick a box for the scale of your concern about local air pollution in the two selected regions displayed in the map.

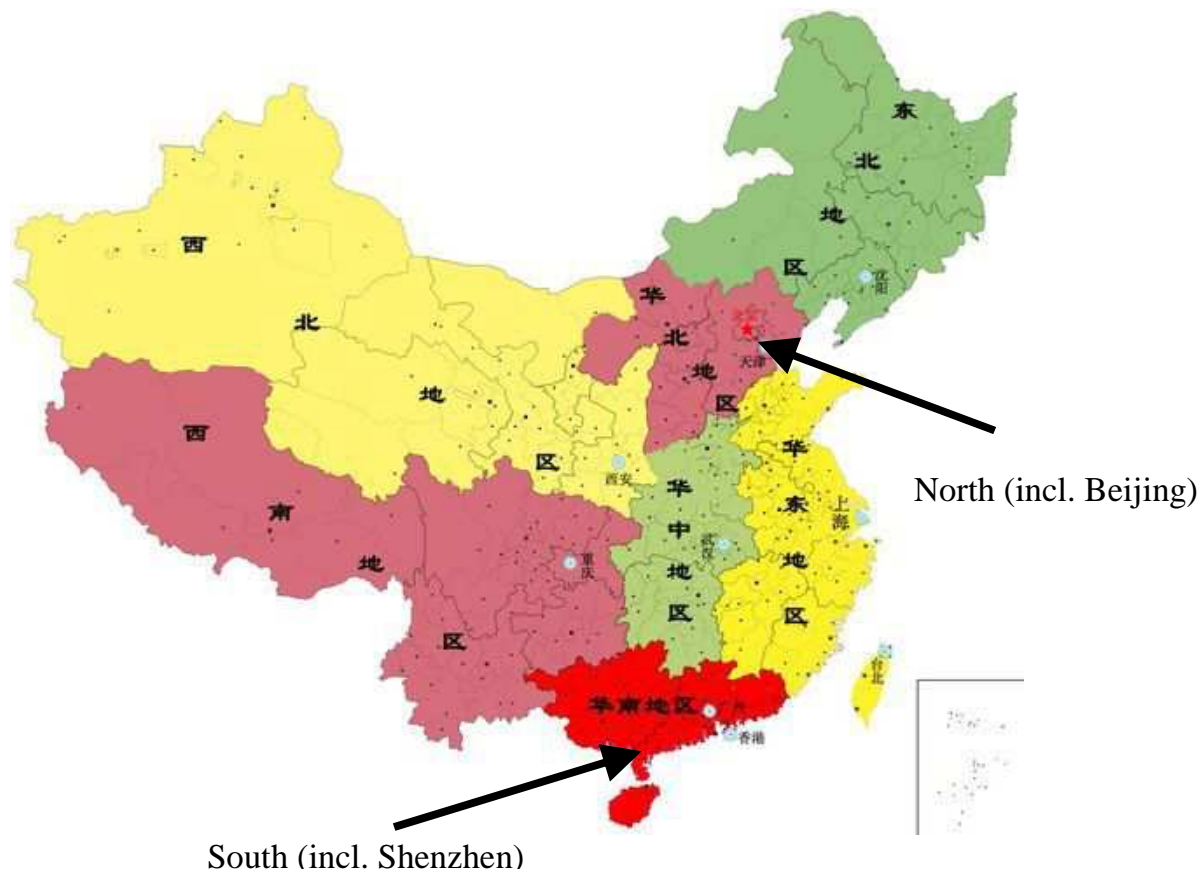

South (incl. Shenzhen)

\begin{tabular}{|c|c|c|c|c|}
\hline & $\begin{array}{c}\text { Not concerned } \\
1\end{array}$ & $\begin{array}{c}\text { Rather not } \\
\text { concerned 2 }\end{array}$ & $\begin{array}{c}\text { Rather } \\
\text { concerned 3 }\end{array}$ & $\begin{array}{c}\text { Concerned } \\
4\end{array}$ \\
\hline North (incl. Beijing) A06_01 & $\bigcirc$ & $\bigcirc$ & $\bigcirc$ & $\bigcirc$ \\
\hline $\begin{array}{c}\text { South (incl. Shenzhen) } \\
\text { A06_02 }\end{array}$ & $\bigcirc$ & $\bigcirc$ & $\bigcirc$ & $\bigcirc$ \\
\hline
\end{tabular}

\section{A07}

How would you describe your knowledge about the following topics?

\begin{tabular}{|l|c|c|c|c|}
\hline & $\begin{array}{c}\text { Poorly } \\
\text { informed 1 }\end{array}$ & $\begin{array}{c}\text { Rather poorly } \\
\text { informed 2 }\end{array}$ & $\begin{array}{c}\text { Rather well } \\
\text { informed 3 }\end{array}$ & $\begin{array}{c}\text { Well informed } \\
4\end{array}$ \\
\hline $\begin{array}{l}\text { Regarding climate change } \\
\text { I am ... A07_01 }\end{array}$ & $\bigcirc$ & $\bigcirc$ & $\bigcirc$ & $\bigcirc$ \\
\hline $\begin{array}{l}\text { Regarding emissions trading } \\
\text { I am ... A07_02 }\end{array}$ & $\bigcirc$ & $\bigcirc$ & $\bigcirc$ & $\bigcirc$ \\
\hline $\begin{array}{l}\text { Regarding local air pollution } \\
\text { I am ... A07_03 }\end{array}$ & $\bigcirc$ & $\bigcirc$ & $\bigcirc$ & $\bigcirc$ \\
\hline
\end{tabular}




\section{General information}

Today, we will offer you a certain product to purchase. In a few minutes you will learn which product it is and how the sale will be conducted.

As we want to assess whether you want to purchase the product, we would like to ask you not to talk to the other participants.

If you have any questions please do not hesitate to contact us.

\section{Rules of purchase}

No one except for the UIBE team will learn about your statements from the event.

The process of sale can be explained in three steps:

i) Introduction of the product

Before we ask you to make a purchase decision, we will briefly introduce the product to you.

ii) Decision to buy for different prices

You will receive different prices for one unit of the product. For each price you can indicate whether you are willing to buy or not (there is no obligation to buy).

iii) Payment

After the decision and after the second questionnaire, one price is randomly selected and the transaction is realized. Please note: If you purchase the product, you will have to use your own money.

In a moment, we will go over a quick example with you.

Please note:

With these rules of purchase it is in your own interest to purchase the product only in case you actually want to buy at the respective price. 


\section{Comprehension Test}

We will now carry out a short test to check whether you have fully understood the rules of purchase. Please let us know, when you have finished answering all questions (i.e. ticked the corresponding box) and we will come to you.

Imagine a participant is willing to pay up to $\mathbf{7 0} \mathbf{~ R M B}$ for the product. He has to decide whether to purchase or not the product for the following six prices. After the decisions one price is randomly selected and the transaction is realized for this price. Please indicate in the table below how the participant should decide in situation 1 below.

\begin{tabular}{|l|l|l|l|}
\hline \multicolumn{2}{|l|}{ Situation 1 } & \multicolumn{2}{|c|}{ Purchase } \\
\hline$\#$ & Price (in RMB) & YES & NO \\
\hline 1 & 100 & $\bigcirc$ & $\bigcirc$ \\
\hline 2 & 80 & $\bigcirc$ & $\bigcirc$ \\
\hline 3 & 60 & $\bigcirc$ & $\bigcirc$ \\
\hline 4 & 40 & $\bigcirc$ & $\bigcirc$ \\
\hline 5 & 20 & $\bigcirc$ & $\bigcirc$ \\
\hline 6 & 10 & $\bigcirc$ & $\bigcirc$ \\
\hline
\end{tabular}

Now assume, a participant is willing to pay up to $\mathbf{3 0} \mathbf{R M B}$ for the product. Please indicate how the participant should decide in situation 2 below.

\begin{tabular}{|l|l|l|l|}
\hline \multicolumn{2}{|l|}{ Situation 2 } & \multicolumn{2}{|c|}{ Purchase } \\
\hline$\#$ & Price (in RMB) & YES & NO \\
\hline 1 & 100 & $\bigcirc$ & $\bigcirc$ \\
\hline 2 & 80 & $\bigcirc$ & $\bigcirc$ \\
\hline 3 & 60 & $\bigcirc$ & $\bigcirc$ \\
\hline 4 & 40 & $\bigcirc$ & $\bigcirc$ \\
\hline 5 & 20 & $\bigcirc$ & $\bigcirc$ \\
\hline 6 & 10 & $\bigcirc$ & $\bigcirc$ \\
\hline
\end{tabular}

Please answer the following questions:

1. What should I do in case I do not want buy the product at all?

I indicate "Yes" for all prices.

I indicate "No" for all prices.

I only indicate "Yes" for the price $10 \mathrm{RMB}$.

2. How many prices will be randomly selected in each situation?

$\begin{array}{ll}\bigcirc & 2 \text { prices } \\ \bigcirc & 5 \text { prices } \\ 1 \text { price }\end{array}$




\section{Information on Climate Change}

Please read the information provided on this page carefully.

You have about 10 minutes to do so.

Global climate change is seen as a serious environmental problem faced by mankind. Human influence on the climate system is clear: mankind largely contributes to climate change by emitting greenhouse gases, especially carbon dioxide $\left(\mathrm{CO}_{2}\right) \cdot \mathrm{CO}_{2}$ originates mainly from burning of fossil fuels like coal, oil or natural gas in industrial processes and energy production, or combustion engines of cars and lorries. $\mathrm{CO}_{2}$ is a global pollutant, i.e. each quantity unit of $\mathrm{CO}_{2}$ emitted has the same effect on the climate regardless of the location where the emission has occurred. Fossil fuel and biofuel combustion is also a very important man-made source of air pollutants like particulate matter (PM2.5 and PM10), sulfur dioxide, nitrogen dioxide or ozone with more localized effects.

Without additional efforts to reduce greenhouse gases emissions beyond those in place today, global mean surface temperature is expected to increase in 2100 in the range from $3.7^{\circ} \mathrm{C}$ to $4.8^{\circ} \mathrm{C}$ above the pre-industrial average.

There are several consequences from rising temperatures. The most important consequences are stated below:

1. Extreme weather events like extreme heat waves, strong rainfalls and tropical storms are likely to become more frequent. Higher damages due to extreme weather events are expected.

2. The oceans will continue to warm and acidify, and global mean sea level to rise. For the period 2081-2100 relative to 1986-2005, the rise will likely be in the ranges of 0.26 to $0.82 \mathrm{~m}$. Thus, low lying coastal regions may be threatened by floods. Sea level rise will not be uniform across regions.

3. The consequences of climate change will vary regionally resulting in substantial consequences for example in agriculture. Countries in the south which today are already hot and dry will become even hotter and dryer. Especially African countries will have to expect lower crop yields.

4. In China the following effects can be expected: The agricultural system may become more vulnerable and food security will be threatened. Coastal cities such as Guangzhou, Shanghai, and Tianjin will face the threat of flooding.

In order to mitigate climate change, reducing $\mathrm{CO}_{2}$ emissions is necessary. Abatement of $\mathrm{CO}_{2}$ is costly. Reducing $\mathrm{CO}_{2}$ emissions, however, can be associated with significant co-benefits from reduced emissions of local air pollutants and related human health and ecosystem impacts.

Sources used:

Intergovernmental Panel on Climate Change (IPCC 2014, AR5)

World Energy Outlook, Energy and Air Pollution (2016) 
Information on Beijing Emissions Trading System (Note: in treatment Beijing)

Please read the information provided on this page carefully.

You will have about 10 minutes to do so.

In 2013 Beijing, together with six pilot provinces/cities (Shanghai, Tianjin, Chongqing, Shenzhen, Guangdong and Hubei), has implemented the emissions trading system (ETS) for carbon dioxide $\left(\mathrm{CO}_{2}\right)$. Emissions trading is one of the instruments of climate policy in China. It follows a simple principle: National Development and Reform Commission (NDRC), jointly with Beijing (and other pilot cities), has determined the amount of $\mathrm{CO}_{2}$ to be emitted altogether in the respective sectors (energy production and energy intensive industries). This total amount will be distributed to the companies in the form of emission rights ("certificates" or "permits"). For each quantity unit of $\mathrm{CO}_{2}$ emitted, the company has to give a certificate to the ETS. The certificates can be traded between companies.

For each quantity unit of $\mathrm{CO}_{2}$ emitted e.g. by a power plant, the plant operator has to prove his permission to do so in the form of a certificate. This leads to an important consequence: If the total amount of certificates is reduced, the total emissions will be lower, simply because plant operators do not possess enough emission allowances. That means if a certificate for one quantity unit is obtained from the market and is being "retired" (i.e. deleted) the total $\mathbf{C O}_{2}$ emissions are reduced by exactly this quantity amount. The opportunity to retire certificates actually exists in the framework of the Emissions Trading System of Beijing. The NDRC regulates emissions trading and holds a retirement account. If certificates are transferred to this account they will be withdrawn from circulation, i.e. deleted, by the end of each year and can no longer be used by the companies.

Emissions trading has one central advantage: It guarantees that the abatement of $\mathrm{CO}_{2}$ emissions occurs where it is the cheapest. Companies with opportunities to abate carbon dioxide at lower costs will do so and sell their certificates on the market, whereas companies with high abatement costs can acquire certificates at a relatively low price. This trade is beneficiary for both sides and guarantees for the emission reduction target to be achieved at minimal costs. The abatement of $\mathrm{CO}_{2}$ emissions in the Beijing emissions trading system is likely to deliver also local air quality improvements as facilities become more energy efficient or switch to cleaner fuels.

Altogether, Beijing energy producers and energy intensive industries were allowed to emit about $\mathbf{4 5}$ million tons of $\mathbf{C O}_{2}$ in the year 2014. As a benchmark: global / China $\mathrm{CO}_{2}$ emissions per year amount for $32.000 / 9.000$ million tons of $\mathrm{CO}_{2}$.

Summarising, it can be stated that if the total amount of certificates in the Beijing Emissions Trading System is reduced, the total $\mathbf{C O}_{2}$ emissions in Beijing decrease affecting also local air pollution. 
Purchase of $\mathrm{CO}_{2}$ Certificates (Note: in treatment Beijing, high price vector)

You are given the opportunity to reduce one ton of $\mathrm{CO}_{2}$ emissions in Beijing by buying one certificate of the Beijing Emissions Trading System at this event. Thus, you have the opportunity to contribute to the reduction of the actual $\mathrm{CO}_{2}$ emissions in Beijing.

The total amount of certificates purchased will be published on the UIBE website (no names or individual purchases will be published). UIBE will buy the amount of certificates chosen and will retire them.

The product is 1 ton of $\mathrm{CO}_{2}$.

In the table below you see 6 prices for one $\mathrm{CO}_{2}$ certificate in Beijing. Please indicate for each price whether you are willing to buy or not. After the decisions and after the second questionnaire, one price is randomly selected and the transaction is realized, i.e. one ton of $\mathrm{CO}_{2}$ in Beijing is deleted.

Important note:

There is no obligation to buy! Certificates purchased by you have to be paid!

\begin{tabular}{|l|l|c|c|}
\hline \multicolumn{2}{|l|}{} & \multicolumn{2}{|c|}{ Purchase buy } \\
\hline$\#$ & Price (in RMB) & YES & NO \\
Pnumber & P & 1 & 0 \\
\hline 1 & 300 & $\bigcirc$ & $\bigcirc$ \\
\hline 2 & 100 & $\bigcirc$ & $\bigcirc$ \\
\hline 3 & 45 & $\bigcirc$ & $\bigcirc$ \\
\hline 4 & 27 & $\bigcirc$ & $\bigcirc$ \\
\hline 5 & 14 & $\bigcirc$ & $\bigcirc$ \\
\hline 6 & 5 & $\bigcirc$ & $\bigcirc$ \\
\hline
\end{tabular}




\section{Questionnaire II (Note: in treatment Beijing, high price vector) Please answer the following questions.}

\section{B00}

We would like to know what you expect regarding the purchase decision of all other subjects in the room. Please indicate the expected proportion of all other subjects who purchase at the given price.

Example: If all other subjects purchase at a given prices, this makes $100 \%$. If the half of all other subject purchase at a given price, this makes $50 \%$.

\begin{tabular}{|c|c|c|}
\hline$\#$ & Price (in RMB) & Purchase of all other participants (in \%) \\
\hline 1 & 300 & \\
\hline 2 & 100 & \\
\hline 3 & 45 & \\
\hline 4 & 27 & \\
\hline 5 & 14 & \\
\hline 6 & 5 & \\
\hline
\end{tabular}

\section{B01}

What do you think is the recent price for $\mathrm{CO}_{2}$ certificates in the Beijing emissions trading scheme?

\begin{tabular}{|c|c|}
\hline RMB & I don't know \\
\hline & $\bigcirc$ \\
\hline
\end{tabular}

\section{B02}

Please indicate how sure you are regarding your price estimate above?

\begin{tabular}{|c|c|c|c|}
\hline Not sure & Rather unsure & Rather sure & Sure \\
1 & 2 & 3 & 4 \\
\hline$\bigcirc$ & $\bigcirc$ & $\bigcirc$ & $\bigcirc$ \\
\hline
\end{tabular}

\section{B03}

Do you trust in the ability of the Beijing emissions trading scheme to limit $\mathrm{CO} 2$ emissions?

\begin{tabular}{|c|c|c|c|}
\hline $\begin{array}{c}\text { Not at all } \\
1\end{array}$ & $\begin{array}{c}\text { I rather do } \\
\text { not trust } 2\end{array}$ & $\begin{array}{c}\text { I rather trust } \\
3\end{array}$ & $\begin{array}{c}\text { I trust } \\
4\end{array}$ \\
\hline & $\bigcirc$ & $\bigcirc$ & $\bigcirc$ \\
\hline
\end{tabular}


C01

Please indicate how you most commonly commute within the city?

\begin{tabular}{|l|c|}
\hline Driving alone with vehicle 1 & 0 \\
\hline Carpooling/carsharing 2 & \\
\hline Driving with motorcycle 3 & \\
\hline Driving with electric bicycle 4 & 0 \\
\hline Park and ride 5 & 0 \\
\hline Public transport 6 & 0 \\
\hline Taxi 7 & 0 \\
\hline Cycling 8 & 0 \\
\hline Walking 9 & \\
\hline
\end{tabular}

C02

Please indicate how many hours per day do you spend commuting in Beijing (round trip)?

\begin{tabular}{|l|c|}
\hline$<0.5$ hours 0.25 & $\bigcirc$ \\
\hline $0.5-10.75$ & $\bigcirc$ \\
\hline $1-1.51 .25$ & $\bigcirc$ \\
\hline $1.5-21.75$ & $\bigcirc$ \\
\hline $2-2.52 .25$ & $\bigcirc$ \\
\hline $2.5-32.75$ & $\bigcirc$ \\
\hline$>33.25$ & $\bigcirc$ \\
\hline
\end{tabular}

C03

Are you generally satisfied with the environmental conditions in Beijing?

\begin{tabular}{|c|c|c|c|}
\hline Not satisfied 1 & Rather not satisfied 2 & Rather satisfied 3 & Satisfied 4 \\
\hline & $\bigcirc$ & $\bigcirc$ & $\bigcirc$ \\
\hline
\end{tabular}

\section{C04}

Are you a member of an environmental organization or are you regularly engaged in activities protecting or enhancing the environment?

\begin{tabular}{|c|c|} 
protecting or enhancing the environment? \\
\hline No 0 & Yes 1 \\
\hline$\bigcirc$ & $\bigcirc$ \\
\hline
\end{tabular}

\section{C05}

Please indicate to what extent do you agree to the following statements regarding your personal responsibility for climate change:

\begin{tabular}{|l|c|c|c|c|}
\hline & $\begin{array}{c}\text { Strongly } \\
\text { Disagree 1 }\end{array}$ & $\begin{array}{c}\text { Disagree } \\
2\end{array}$ & $\begin{array}{c}\text { Agree } \\
3\end{array}$ & $\begin{array}{c}\text { Strongly } \\
\text { Agree 4 }\end{array}$ \\
\hline $\begin{array}{l}\text { It is pointless if I do something against } \\
\text { climate change as an individual } \\
\text { C05_01 }\end{array}$ & $\bigcirc$ & $\bigcirc$ & $\bigcirc$ & $\bigcirc$ \\
\hline $\begin{array}{l}\text { I don't buy fruits and vegetables from } \\
\text { far away to save emissions C05_02 }\end{array}$ & $\bigcirc$ & $\bigcirc$ & $\bigcirc$ & $\bigcirc$ \\
\hline $\begin{array}{l}\text { I feel obliged to consider the climate } \\
\text { impact of my daily activities C05_03 }\end{array}$ & $\bigcirc$ & $\bigcirc$ & $\bigcirc$ & $\bigcirc$ \\
\hline $\begin{array}{l}\text { I feel better when I save emissions } \\
\text { C05_04 }\end{array}$ & $\bigcirc$ & $\bigcirc$ & $\bigcirc$ & $\bigcirc$ \\
\hline $\begin{array}{l}\text { I have a bad conscience when I drive a } \\
\text { car instead of using public transport } \\
\text { C05_05 }\end{array}$ & $\bigcirc$ & $\bigcirc$ & $\bigcirc$ & $\bigcirc$ \\
\hline $\begin{array}{l}\text { In my daily activities I try to save as } \\
\text { many emissions as I can C05_06 }\end{array}$ & $\bigcirc$ & $\bigcirc$ & $\bigcirc$ & $\bigcirc$ \\
\hline
\end{tabular}


D01

Please indicate your gender.

\begin{tabular}{|l|c|}
\hline Female 1 & $\bigcirc$ \\
\hline Male 0 & $\bigcirc$ \\
\hline
\end{tabular}

\section{D02}

Please indicate your marital status.

\begin{tabular}{|c|c|c|c|c|}
\hline Single 1 & Divorced 2 & Married 3 & Widow/er 4 & Separated 5 \\
\hline$\bigcirc$ & $\bigcirc$ & $\bigcirc$ & $\bigcirc$ & $\bigcirc$ \\
\hline
\end{tabular}

\section{D03}

Please indicate your year of birth.

\section{D04}

Please indicate your current living/home address in Beijing (district, street)

\section{D05}

Please indicate your highest education level attained.

\begin{tabular}{|l|c|}
\hline Not educated 1 & $\bigcirc$ \\
\hline Elementary 2 & $\bigcirc$ \\
\hline Junior High School 3 & $\bigcirc$ \\
\hline Senior High School 4 & $\bigcirc$ \\
\hline Vocational High School 5 & $\bigcirc$ \\
\hline College 6 & $\bigcirc$ \\
\hline University (Bachelor) 7 & $\bigcirc$ \\
\hline University (Master) 8 & $\bigcirc$ \\
\hline University (Doctorate) 9 & $\bigcirc$ \\
\hline Adult Education, Open University, Evening school 10 & \\
\hline Other(s): Please specify 11 & \\
\hline
\end{tabular}

\section{D06}

Please indicate which category best describes your current labor or schooling situation?

\begin{tabular}{|l|c|}
\hline Working 1 & \\
\hline Job searching 2 & \\
\hline Attending school 3 & \\
\hline Housekeeping 4 & $\bigcirc$ \\
\hline Retired 5 & $\bigcirc$ \\
\hline Sick/disable 6 & $\bigcirc$ \\
\hline On vacation/just graduated 7 & \\
\hline Other(s): Please specify 8 & \\
\hline
\end{tabular}

D07

If it is the case that you work: Please indicate which category best describes your current occupation?

\begin{tabular}{|l|c|}
\hline Employed (whole time) 1 & $\bigcirc$ \\
\hline Employed (part time) 2 & $\bigcirc$ \\
\hline Self-employed 3 & $\bigcirc$ \\
\hline Government worker 4 & $\bigcirc$ \\
\hline Casual worker 5 & \\
\hline Other(s): Please specify 6 & \\
\hline
\end{tabular}




\section{D08}

Please indicate your current working/studying address in Beijing (district, street)

\section{D09}

Please indicate how many children (younger than 18 years) live in your household?

\section{D10}

Please indicate how many young children (under 6 years old) live in your household?

\section{D11}

Are you a member of communist party of China?

\begin{tabular}{|c|c|}
\hline No 0 & Yes 1 \\
\hline$\bigcirc$ & $\bigcirc$ \\
\hline
\end{tabular}

\section{D12}

What is your religion?

\begin{tabular}{|l|c|}
\hline Buddhist 1 & \\
\hline Taoist 2 & $\bigcirc$ \\
\hline Christian 3 & \\
\hline Catholic 4 & $\bigcirc$ \\
\hline Islam 5 & $\bigcirc$ \\
\hline None 6 & $\bigcirc$ \\
\hline Other(s): Please specify 7 & \\
\hline
\end{tabular}

\section{D13}

Please indicate your average monthly wage after taxes.

\begin{tabular}{|l|r|}
\hline Less than 1000 RMB 0.5 & \\
\hline 1000 to less than 2000 RMB 1.5 & $\bigcirc$ \\
\hline 2000 to less than 4000 RMB 3 & $\bigcirc$ \\
\hline 4000 to less than 6000 RMB 5 & $\bigcirc$ \\
\hline 6000 to less than 8000 RMB 7 & $\bigcirc$ \\
\hline 8000 to less than 10000 RMB 9 & $\bigcirc$ \\
\hline 10000 to less than 20000 RMB 15 & $\bigcirc$ \\
\hline More than 20000 RMB 25 & $\bigcirc$ \\
\hline Don't know nA & \\
\hline
\end{tabular}

\section{D14}

Please indicate your average monthly household income after taxes (including wages, interests, dividends, real estate income, rent/lease/profit sharing of household assets, retirement pension, scholarship and insurance money)

\begin{tabular}{|l|r|}
\hline Less than 1000 RMB 0.5 & $\bigcirc$ \\
\hline 1000 to less than 2000 RMB 1.5 & $\bigcirc$ \\
\hline 2000 to less than 4000 RMB 3 & $\bigcirc$ \\
\hline 4000 to less than 6000 RMB 5 & $\bigcirc$ \\
\hline 6000 to less than 8000 RMB 7 & $\bigcirc$ \\
\hline 8000 to less than 10000 RMB 9 & $\bigcirc$ \\
\hline 10000 to less than 20000 RMB 15 & $\bigcirc$ \\
\hline More than 20000 RMB 25 & $\bigcirc$ \\
\hline Don't know nA & \\
\hline
\end{tabular}




\section{Leaving the room}

Please leave the room only after we invite you to do so. Please take the instructions with you and hand them out to the research assistant who will take care of you at the exit.

We will randomly select one price before you are leaving the room and you will pay for your purchase decision outside the room in case you decided to purchase at the selected price.

Thank you for your participation! 


\section{Appendix 3: Descriptive analysis of questionnaire data}

The total number of observations is $n=317$.

Table A3_1a: Questionnaire A before the decision

Description

A01: Taking all things together, how happy are you these days? Please tick a box on the scale, where the value 1 means: 'not at all happy' and the value 10 means: 'very happy'.

A02: All in all, how would you describe your state of health these days? Please tick a box on the scale, where the value 1 means: 'poor' and the value 10 means: 'very good'.

A03: All things considered, how satisfied are you with your life as a whole these days? Please tick a box on the scale, where the value 1 means: 'completely dissatisfied' and the value 10 means: 'completely satisfied'.

A04: Are you generally a person who is fully prepared to take risks or do you try to avoid taking risks? Please tick a box on the scale, where the value 1 means: 'unwilling to take risks' and the value 10 means: 'fully prepared to take risks'.

\begin{tabular}{rrr} 
Mean & Std.Dev. & Missing \\
\hline 7.74 & 1.72 & 0
\end{tabular}

7.44

Table A3_1b: Questionnaire A before the decision $(1=$ Not concerned, $2=$ Rather not concerned, 3 = Rather concerned, 4 = Concerned)

Description

A05: Are you generally concerned about human-induced climate

\begin{tabular}{rrr} 
Mean & Std.Dev. & Missing \\
\hline 3.31 & 0.63 & 0
\end{tabular}
change?

A06_01: Are you generally concerned about local air pollution in the north (incl. Beijing) caused by pollutants like for example particulate matter (PM2.5 and PM10), sulfur dioxide, nitrogen dioxide or ozone?

A06_02: Are you generally concerned about local air pollution in the south (incl. Shenzhen) caused by pollutants like for example particulate matter (PM2.5 and PM10), sulfur dioxide, nitrogen dioxide or ozone?

Table A3_1c: Questionnaire A before the decision $(1=$ Poorly informed, 2 = Rather poorly informed, 3 = Rather well informed, $4=$ Well informed)

Description

A07_01: How would you describe your knowledge about the following \begin{tabular}{rrr} 
Mean & Std.Dev. & Missing \\
\hline 2.66 & 0.67 & 2
\end{tabular} topics? Regarding climate change I am...

A07_02: How would you describe your knowledge about the following $\quad 2.02 \quad 0.76 \quad 2$ topics? Regarding emissions trading I am...

A07_03: How would you describe your knowledge about the following $\quad \begin{array}{llll}2.61 & 0.70 & 0\end{array}$ topics? Regarding local air pollution I am... 
Table A3_2a: Questionnaire B after the decision

I don't

\begin{tabular}{|c|c|c|c|c|c|c|c|c|}
\hline Description & Min & Q1 & Median & Mean & Q3 & Max & Std.Dev. & know/Missing \\
\hline $\begin{array}{l}\text { B01 Beijing: What do } \\
\text { you think is the recent } \\
\text { price (in RMB) for } \\
\text { CO2 certificates in } \\
\text { the Beijing emissions } \\
\text { trading scheme? } \mathrm{n}= \\
222\end{array}$ & 2 & 23.75 & 100 & 5093.24 & 300 & 100000 & 21020.73 & 178 \\
\hline $\begin{array}{l}\text { B01 Shenzhen: What } \\
\text { do you think is the } \\
\text { recent price (in RMB) } \\
\text { for CO2 certificates } \\
\text { in the Shenzhen } \\
\text { emissions trading } \\
\text { scheme?, } \mathrm{n}=95\end{array}$ & 5 & 35.00 & 85 & 195.48 & 200 & 2000 & 432.68 & 75 \\
\hline
\end{tabular}

Table A3_2b: Questionnaire B after the decision (answers for Beijing and Shenzhen are pooled). $1=$ Not sure, 2 = Rather unsure, $3=$ Rather sure, $4=$ Sure

\begin{tabular}{lrrr} 
Description & Mean & Std.Dev. & Missing \\
\hline B02: Please indicate how sure you are regarding your price estimate & 1.67 & 1.02 & 16
\end{tabular} above.

Table A3_2c: Questionnaire B after the decision (answers for Beijing and Shenzhen are pooled). $1=$ Not at all, 2 = I rather do not trust, 3 = I rather trust, $4=$ I trust)

Description $\quad$ Mean Std.Dev. Missing trading scheme to limit $\mathrm{CO} 2$ emissions?

Table A3_3a: Questionnaire C after the decision (C01: Please indicate how you most commonly commute within the city?)

Category Proportion

Driving alone with vehicle $\quad 0.101$

Carpooling/carsharing $\quad 0.000$

Driving with motorcycle $\quad 0.009$

Driving with electric bicycle $\quad 0.028$

Park and ride $\quad 0.019$

Public transport $\quad 0.644$

Taxi 0.000

Cycling $\quad 0.129$

Walking $\quad 0.069$

Missing $\quad 0.000$ 
Table A3_3b: Questionnaire C after the decision (C02: Please indicate how many hours per day do you spend commuting in Beijing (round trip)?)

Category Proportion

\begin{tabular}{ll}
\hline$[0,0.5)$ & 0.110 \\
{$[0.5,1)$} & 0.287 \\
{$[1,1.5)$} & 0.221 \\
{$[1.5,2)$} & 0.164 \\
{$[1,2.5)$} & 0.126 \\
{$[2.5,3)$} & 0.050 \\
$>=3$ & 0.038 \\
Missing & 0.003
\end{tabular}

Table A3_3c: Questionnaire C after the decision. 1 = Not satisfied, 2 = Rather not satisfied, $3=$ Rather satisfied, $4=$ Satisfied

Description \begin{tabular}{rrr} 
Mean & Std.Dev. & Missing \\
\hline 1.82 & 0.72 & 0
\end{tabular}

C03: Are you generally satisfied with the environmental conditions in Beijing?

Table A3_3d: Questionnaire C after the decision. $1=$ Yes, $0=$ No

Description Mean Std.Dev. Missing

C04: Are you a member of an environmental organization or are you

$0.24 \quad 0.43$

regularly engaged in activities protecting or enhancing the environment?

Table A3_3e: Questionnaire $\mathrm{C}$ after the decision (C05: Please indicate to what extent do you agree to the following statements regarding your personal responsibility for climate change. $1=$ Strongly Disagree, $2=$ Disagree, $3=$ Agree, $4=$ Strongly agree)

Description

\begin{tabular}{rrr} 
Mean & Std.Dev. & Missing \\
\hline 1.82 & 0.89 & 0
\end{tabular}
individual.

C05_02: I don't buy fruits and vegetables from far away to save $2.23 \quad 0.88$ emissions.

C05_03: I feel obliged to consider the climate impact of my daily activities.

C05_04: I feel better when I save emissions.

C05_05: I have a bad conscience when I drive a car instead of using

$2.31 \quad 0.91$
public transport.

C05_06: In my daily activities I try to save as many emissions as I can. $\begin{array}{llll}3.54 & 0.63 & 0\end{array}$

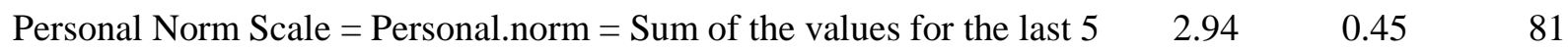
questions above divided by 5

Table A3_4a: Questionnaire D after the decision

\begin{tabular}{lrrr} 
Description & Mean & Std.Dev. & Missing \\
\hline D01: Please indicate your gender. $1=$ Female, $0=$ Male & 0.64 & 0.48 & 0
\end{tabular}


Table A3_4b: Questionnaire D after the decision (D02: Please indicate your marital status.)

\begin{tabular}{lr} 
Category & Proportion \\
\hline Single & 0.303
\end{tabular}

Divorced $\quad 0.025$

Married $\quad 0.656$

Widow/er $\quad 0.009$

Separated $\quad 0.006$

Missing $\quad 0.000$

Table A3_4c: Questionnaire D after the decision

\begin{tabular}{lrrrrrrrr} 
Description & Min & Q1 & Median & Mean & Q3 & Max & Std.Dev. & Missing \\
\hline $\begin{array}{l}\text { D03: Please indicate your year } \\
\text { of birth }\end{array}$ & 1940 & 1962 & 1981 & 1975.77 & 1989 & 1998 & 14.64 & 2 \\
Age & 19 & 28 & 36 & 41.23 & 55 & 74 & 14.64 & 2
\end{tabular}

Table A3_4d: Questionnaire D after the decision (D05: Please indicate your highest education level attained.)

\begin{tabular}{lr} 
Category & Proportion \\
\hline Not educated & 0.000 \\
Elementary & 0.006 \\
Junior High School & 0.076 \\
Senior High School & 0.126 \\
Vocational High School & 0.022 \\
College & 0.158 \\
University (Bachelor) & 0.397 \\
University (Master) & 0.174 \\
University (Doctorate) & 0.013 \\
Adult Education, Open University, Evening school & 0.028 \\
Other & 0.000 \\
Missing & 0.000
\end{tabular}

Table A3_4e: Questionnaire D after the decision (D06: Please indicate which category best describes your current labor or schooling situation.)

\begin{tabular}{lr} 
Category & Proportion \\
\hline Working & 0.653 \\
Job searching & 0.013 \\
Attending school & 0.054 \\
Housekeeping & 0.013 \\
Retired & 0.259 \\
Sick/disable & 0.006 \\
On vacation/just graduated & 0.000 \\
Other & 0.000 \\
Missing & 0.003
\end{tabular}


Table A3_4f: Questionnaire D after the decision (D07: If it is the case that you work: Please indicate which category best describes your current occupation?)

Category Proportion

$\begin{array}{ll}\text { Employed (whole time) } & 0.612 \\ \text { Employed (part time) } & 0.035 \\ \text { Self-employed } & 0.019 \\ \text { Government worker } & 0.032 \\ \text { Casual worker } & 0.054 \\ \text { Other } & 0.009 \\ \text { Missing } & 0.240\end{array}$

Table A3_4g: Questionnaire D after the decision

Description

$\begin{array}{rrrrrrrr}\text { Min } & \text { Q1 } & \text { Median } & \text { Mean } & \text { Q3 } & \text { Max } & \text { Std.Dev. } & \text { Missing } \\ 0 & 0 & 0 & 0.29 & 1 & 2 & 0.49 & 9\end{array}$

D09: Please indicate how many

children (younger than 18 years) live

in your household?

$\begin{array}{lllllllll}\text { D10: Please indicate how many } & 0 & 0 & 0 & 0.19 & 0 & 2 & 0.43 & 9\end{array}$ children (younger than 6 years) live in your household?

Table A3_4h: Questionnaire D after the decision

Description Mean Std.Dev. Missing

D11: Are you a member of communist party of China? $1=$ Yes, $0=$ No $\begin{array}{llll}0.32 & 0.47 & 0\end{array}$

Table A3_4i: Questionnaire D after the decision (D12: What is your religion?)

\begin{tabular}{lr} 
Category & Proportion \\
\hline Buddhist & 0.063 \\
Taoist & 0.003 \\
Christian & 0.006 \\
Catholic & 0.006 \\
Islam & 0.003 \\
None & 0.861 \\
Other & 0.000
\end{tabular}

Missing $\quad 0.057$

Table A3_4j: Questionnaire D after the decision (D13: Please indicate your average monthly wage after taxes.)

\begin{tabular}{lr} 
Category & Proportion \\
\hline$[0,1000)$ & 0.019 \\
{$[1000,2000)$} & 0.054 \\
{$[2000,4000)$} & 0.287 \\
{$[4000,6000)$} & 0.199 \\
{$[6000,8000)$} & 0.132 \\
{$[8000,10000)$} & 0.117 \\
{$[10000,20000)$} & 0.110 \\
$>20000$ & 0.022 \\
Missing & 0.054
\end{tabular}


Table A3_4k: Questionnaire D after the decision (D14: Please indicate your average monthly household Income after taxes (including wages, interests, dividends, real estate income, rent/lease/profit sharing of household assets, retirement pension, scholarship and insurance money))

Category Proportion

\begin{tabular}{ll}
\hline$[0,1000)$ & 0.000 \\
{$[1000,2000)$} & 0.013 \\
{$[2000,4000)$} & 0.088 \\
{$[4000,6000)$} & 0.104 \\
{$[6000,8000)$} & 0.148 \\
{$[8000,10000)$} & 0.120 \\
{$[10000,20000)$} & 0.240 \\
$>$ 20000 & 0.196 \\
Missing & 0.082
\end{tabular}




\section{Appendix 4: Additional econometric models and estimates}

Table A4_1: Logistic regression for treatment effects (Beijing vs. Shenzhen)

\begin{tabular}{|c|c|c|c|c|}
\hline & Model 5 & Model 6 & Model 7 & Model 4 RE \\
\hline $\mathrm{P}$ & $0.97(0.01)^{* * *}$ & $0.97(0.01)^{* *}$ & $0.96(0.01)^{* * *}$ & $0.95(0.01)^{* * *}$ \\
\hline BeijingxP.eol.5 & & & & $13.12(7.26)^{* * * *}$ \\
\hline BeijingxP.larger.5 & & & & $0.91(0.45)$ \\
\hline BeijingxP.eol.14 & $2.28(0.65)^{* *}$ & & & \\
\hline BeijingxP.larger.14 & $0.83(0.28)$ & & & \\
\hline BeijingxP.eol.27 & & $1.71(0.47)$ & & \\
\hline BeijingxP.larger.27 & & $0.79(0.35)$ & & \\
\hline BeijingxP.eol.45 & & & $1.41(0.38)$ & \\
\hline BeijingxP.larger.45 & & & $1.86(1.46)$ & \\
\hline Female & $0.79(0.21)$ & $0.80(0.21)$ & $0.80(0.21)$ & $0.73(0.35)$ \\
\hline Age & $0.97(0.01)$ & $0.97(0.01)$ & $0.97(0.01)$ & $0.95(0.02)^{*}$ \\
\hline Income & $1.03(0.03)$ & $1.03(0.03)$ & $1.03(0.03)$ & $1.06(0.05)$ \\
\hline Academic.degree & $1.82(0.74)$ & $1.78(0.71)$ & $1.74(0.70)$ & $2.86(1.85)$ \\
\hline Commuting.time & $1.02(0.15)$ & $1.02(0.14)$ & $1.01(0.14)$ & $1.07(0.32)$ \\
\hline Religion & $2.18(0.80)^{*}$ & $2.17(0.79)^{*}$ & $2.17(0.80)^{*}$ & $4.21(3.41)$ \\
\hline Risk & $1.25(0.07)^{* * *}$ & $1.25(0.07)^{* * *}$ & $1.25(0.07)^{* * *}$ & $1.47(0.16)^{* *}$ \\
\hline Party & $1.35(0.33)$ & $1.34(0.32)$ & $1.33(0.32)$ & $1.71(0.78)$ \\
\hline Kids.between.6.18 & $0.32(0.16)^{*}$ & $0.33(0.16)^{*}$ & $0.33(0.16)^{*}$ & $0.11(0.10)^{* *}$ \\
\hline Kids.below.6 & $0.91(0.29)$ & $0.91(0.29)$ & $0.91(0.29)$ & $0.94(0.53)$ \\
\hline Trust.in.ETS & $2.68(0.64)^{* * *}$ & $2.63(0.62)^{* * *}$ & $2.61(0.60)^{* * *}$ & $7.52(3.72)^{* * *}$ \\
\hline Dilemma.awareness & $0.88(0.31)$ & $0.89(0.31)$ & $0.89(0.30)$ & $0.89(0.52)$ \\
\hline Personal.norm & $0.83(0.24)$ & $0.84(0.24)$ & $0.85(0.24)$ & $0.74(0.37)$ \\
\hline Concern.climate.change & $0.97(0.25)$ & $0.98(0.24)$ & $0.99(0.24)$ & $0.99(0.51)$ \\
\hline Concern.pollution.north & $1.12(0.34)$ & $1.11(0.33)$ & $1.11(0.33)$ & $1.41(0.77)$ \\
\hline Concern.pollution.south & $1.11(0.39)$ & $1.10(0.38)$ & $1.07(0.37)$ & $0.86(0.57)$ \\
\hline Num. obs. & 1543 & 1543 & 1543 & 1543 \\
\hline Pseudo R2 & 0.313 & 0.305 & 0.300 & \\
\hline Roh & & & & $0.675^{* * *}$ \\
\hline
\end{tabular}

Notes: ${ }^{* * *} \mathrm{p}<0.001,{ }^{* *} \mathrm{p}<0.01,{ }^{*} \mathrm{p}<0.05$. Purchase of certificate is the dependent variable, coefficients are presented as odds ratios. Standard errors in parenthesis are corrected for clustered observations in model 5-7. Model 4 RE uses a random effects structure with the subject $(n=258)$ as the panel variable.

Table A4_2: Average marginal effects and elasticities

\begin{tabular}{lcccccc}
\hline & \multicolumn{2}{c}{ All observations } & \multicolumn{2}{c}{ Beijing } & \multicolumn{2}{c}{ Shenzhen } \\
\hline prices & $M E$ & $\eta_{P r}$ & $M E$ & $\eta_{P r}$ & $M E$ & $\eta_{P r}$ \\
\cline { 2 - 6 }$[2,14]$ & $-0.027^{* *}$ & $-0.739^{* *}$ & $-0.034^{* *}$ & $-0.958^{* *}$ & $-0.018^{* *}$ & $-0.636^{* *}$ \\
& $(0.003)$ & $(0.117)$ & $(0.004)$ & $(0.159)$ & $(0.005)$ & $(0.211)$ \\
{$[2,45]$} & $-0.011^{* *}$ & $-1.112^{* *}$ & $-0.012^{* *}$ & $-1.217^{* *}$ & $-0.008^{* *}$ & $-1.156^{* *}$ \\
& $(0.001)$ & $(0.134)$ & $(0.001)$ & $(0.175)$ & $(0.001)$ & $(0.227)$ \\
{$[2,300]$} & $-0.005^{* *}$ & $-2.540^{* *}$ & $-0.006^{* *}$ & $-3.029^{* *}$ & $-0.003^{* *}$ & $-2.059^{*}$ \\
& $(0.001)$ & $(0.569)$ & $(0.001)$ & $(0.756)$ & $(0.001)$ & $(0.863)$ \\
\hline
\end{tabular}

Notes: Average marginal effect of the price on the probability to buy $(M E)$ and average elasticity of the probability of contributing $\left(\eta_{P r}\right)$. Specification with price and socio-economic covariates as the explanatory variables (model 4 in Table 8, except for the Beijing treatment dummy). Standard errors in parentheses are corrected for clustered observations. ${ }^{*} \mathrm{p}<0.01,{ }^{*} \mathrm{p}<0.05$. 


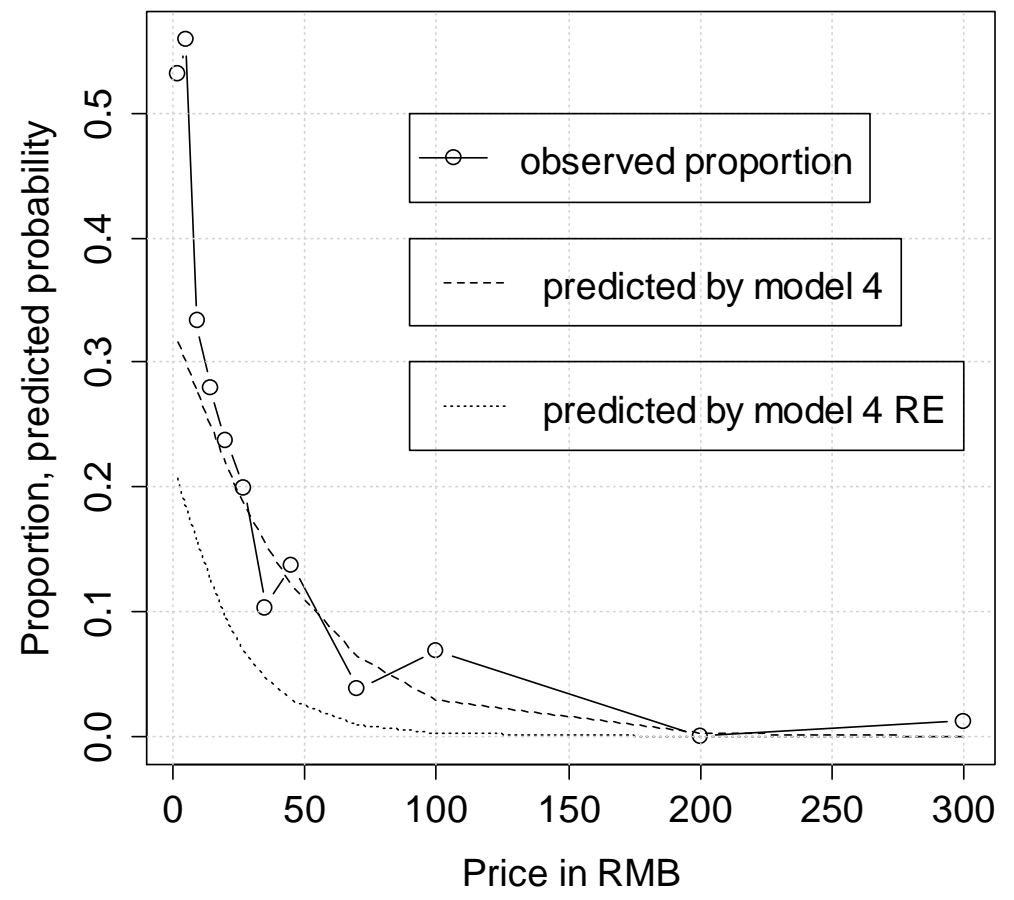

Figure 5: Observed vs. predicted probabilities to purchase - model 4 and model 4 RE 


\section{Appendix 5: Calculation of the Lower-Bound Turnbull WTP}

The lower-bound Turnbull (LBT) is computed in the following steps (see Haab and McConnel 2003):

1. Calculate for each bid level $t_{j}, j=1, \ldots, M$, the share of no answers: $F_{j}=N_{j} / T_{j}$.

2. Compare $F_{j}$ with $F_{j+1}$, if $F_{j}<F_{j+1}$ continue, if $F_{j} \geq F_{j+1}$, these cells are pooled and the combined no shares of these cells calculated: $F_{j}^{*}=N_{j}^{*} / T_{j}^{*}$.

3. This is repeated until a monotonously increasing cdf is formed. Set $F_{M+1}^{*}=1$.

4. Calculate $f_{j+1}^{*}=F_{j+1}^{*}-F_{j}^{*}$ for each bid level $t_{j}$. This corresponds to a consistent estimator of the probability that WTP falls between the price $j$ and price $j+1$.

5. Multiply every bid with the according probability that WTP falls between this bid and the next higher bid.

6. Sum over the quantities of step 5 to obtain lower bound Turnbull WTP, which is then: $E_{L B T}(W T P)=\sum_{j=0}^{M} t_{j}\left(F_{j+1}^{*}-F_{j}^{*}\right)$, and can be interpreted analogous to the consumer surplus as sum of the marginal value multiplied by the adapted quantities, or the integer over the quantity of a demand curve.

7. Calculate the variance: $V\left(E_{L B T}\right)=\sum_{j=1}^{M^{*}} \frac{F_{j}^{*}\left(1-F_{j}^{*}\right)}{T_{j}^{*}}\left(t_{j}-t_{j-1}\right)^{2}$, where $T_{j}^{*}$ is the common amount of observations of the eventually pooled bid cell.

Table A5_1: Lower-bound Turnbull WTP for all observations

\begin{tabular}{rrrrrrrr}
\hline$t_{j}$ & $N_{j}$ & $T_{j}$ & $F_{j}$ & $F_{j}^{*}$ & $f_{j}^{*}$ & $E_{L B T}$ & $V\left(E_{L B T}\right)$ \\
\hline 2 & 73 & 156 & 0.468 & 0.454 & 0.454 & 0.000 & 0.003 \\
5 & 71 & 161 & 0.441 & $\mathrm{p}$ & & & \\
9 & 104 & 156 & 0.667 & 0.667 & 0.212 & 0.425 & 0.070 \\
14 & 116 & 161 & 0.720 & 0.720 & 0.054 & 0.484 & 0.031 \\
20 & 119 & 156 & 0.763 & 0.763 & 0.042 & 0.593 & 0.042 \\
27 & 129 & 161 & 0.801 & 0.801 & 0.038 & 0.768 & 0.048 \\
35 & 140 & 156 & 0.897 & 0.880 & 0.079 & 2.130 & 0.021 \\
45 & 139 & 161 & 0.863 & $\mathrm{p}$ & & & \\
70 & 150 & 156 & 0.962 & 0.946 & 0.066 & 2.319 & 0.196 \\
100 & 150 & 161 & 0.932 & $\mathrm{p}$ & & & \\
200 & 156 & 156 & 1.000 & 0.994 & 0.047 & 3.312 & 0.334 \\
300 & 159 & 161 & 0.988 & $\mathrm{p}$ & & & \\
& & & 1.000 & 1.000 & 0.006 & 1.262 & \\
\hline
\end{tabular}

Note: $\mathrm{p}=$ pooled category.

Linearly interpolated median $=2+(0.5-0.454) *(9-2) /(0.667-0.454)=3.51$. 
Table A5_2: Lower-bound Turnbull WTP for treatment Beijing

\begin{tabular}{rrrrrrrr}
\hline$t_{j}$ & $N_{j}$ & $T_{j}$ & $F_{j}$ & $F_{j}^{*}$ & $f_{j}^{*}$ & $E_{L B T}$ & $V\left(E_{L B T}\right)$ \\
\hline 2 & 44 & 107 & 0.411 & 0.401 & 0.401 & 0.000 & 0.004 \\
5 & 45 & 115 & 0.391 & $\mathrm{p}$ & & & \\
9 & 68 & 107 & 0.636 & 0.636 & 0.235 & 0.469 & 0.106 \\
14 & 82 & 115 & 0.713 & 0.713 & 0.078 & 0.698 & 0.044 \\
20 & 80 & 107 & 0.748 & 0.748 & 0.035 & 0.485 & 0.063 \\
27 & 92 & 115 & 0.800 & 0.800 & 0.052 & 1.047 & 0.068 \\
35 & 96 & 107 & 0.897 & 0.878 & 0.078 & 2.116 & 0.031 \\
45 & 99 & 115 & 0.861 & $\mathrm{p}$ & & & \\
70 & 103 & 107 & 0.963 & 0.950 & 0.072 & 2.523 & 0.260 \\
100 & 108 & 115 & 0.939 & $\mathrm{p}$ & & & \\
200 & 107 & 107 & 1.000 & 0.995 & 0.045 & 3.153 & 0.341 \\
300 & 114 & 115 & 0.991 & $\mathrm{p}$ & & & \\
& & & 1.000 & 1.000 & 0.005 & 0.901 & \\
\hline
\end{tabular}

Note: $\mathrm{p}=$ pooled category.

Linearly interpolated median $=2+(0.5-0.401) *(9-2) /(0.636-0.401)=4.95$.

Table A5_3: Lower-bound Turnbull WTP for treatment Shenzhen

\begin{tabular}{rrrrrrrr}
\hline$t_{j}$ & $N_{j}$ & $T_{j}$ & $F_{j}$ & $F_{j}^{*}$ & $f_{j}^{*}$ & $E_{L B T}$ & $V\left(E_{L B T}\right)$ \\
\hline 2 & 29 & 49 & 0.592 & 0.579 & 0.579 & 0.000 & 0.010 \\
5 & 26 & 46 & 0.565 & $\mathrm{p}$ & & & \\
9 & 36 & 49 & 0.735 & 0.735 & 0.156 & 0.311 & 0.195 \\
14 & 34 & 46 & 0.739 & 0.739 & 0.004 & 0.040 & 0.105 \\
20 & 39 & 49 & 0.796 & 0.796 & 0.057 & 0.795 & 0.119 \\
27 & 37 & 46 & 0.804 & 0.804 & 0.008 & 0.169 & 0.168 \\
35 & 44 & 49 & 0.898 & 0.884 & 0.080 & 2.156 & 0.069 \\
45 & 40 & 46 & 0.870 & $\mathrm{p}$ & & & \\
70 & 47 & 49 & 0.959 & 0.937 & 0.053 & 1.842 & 0.763 \\
100 & 42 & 46 & 0.913 & $\mathrm{p}$ & & & \\
200 & 49 & 49 & 1.000 & 0.989 & 0.053 & 3.684 & 1.853 \\
300 & 45 & 46 & 0.978 & $\mathrm{p}$ & & & \\
& & & 1.000 & 1.000 & 0.011 & 2.105 & \\
\hline
\end{tabular}

Note: $p=$ pooled category.

Linearly interpolated median $=0.5 * 2 / 0.579=1.73$. 